\title{
Preparation and Characterization of Ultra-Thin Dicing Blades With Different Bonding Properties
}

\section{Zewei Yuan ( $\nabla$ zwyuan@aliyun.com )}

Shenyang University of Technology

\section{Shuang Feng}

Shenyang University of Technology

\section{Tianzheng Wu}

Shenyang University of Technology

\section{Research Article}

Keywords: dicing blade, bonding properties, cutting parameters, cutting force model, preparation

Posted Date: October 28th, 2021

DOI: https://doi.org/10.21203/rs.3.rs-997935/v1

License: (1) This work is licensed under a Creative Commons Attribution 4.0 International License. Read Full License

Version of Record: A version of this preprint was published at The International Journal of Advanced Manufacturing Technology on January 22nd, 2022. See the published version at https://doi.org/10.1007/s00170-022-08760-w. 


\title{
Preparation and characterization of ultra-thin dicing blades with different bonding properties
}

\author{
Zewei Yuan, ${ }^{\mathrm{a},}$, Shuang Feng ${ }^{\mathrm{a}}$, Tianzheng $\mathrm{Wu}^{\mathrm{a}}$ \\ ${ }^{a}$ School of Mechanical Engineering, Shenyang University of Technology, Shenyang 110870, China; \\ *Corresponding author. E-mail address: zwyuan@sut.edu.cn (Zewei Yuan)
}

Abstract: Ultra-thin dicing blade is usually used to achieve a high precision cutting in semiconductor back-end packaging and assembly. Lots of interactional parameters involving in dicing blade preparation and cutting process bring difficulties to high cutting qualities and good working life of dicing blade. In order to address these problems, this study prepared three kinds of dicing blades and characterized the cutting properties of three dicing blades. It first proposed the abrasive exposure coefficient and tool deviation coefficient to provide parameters for the cutting force model. Then the experimental apparatus was set up to verify the proposed cutting force model. And a series of parameters including feed rate, spindle current, edge chipping coefficient, tool wear amount and grinding performance are used to characterize the comprehensive performance of prepared dicing blades. Finally, the edge morphology was observed under $3 \mathrm{D}$ microscope to analysis the hardness of different dicing blades. The theoretical and experimental results indicate that the proposed cutting force model can reflect actual cutting process. There is an inverse proportional function between the shedding of abrasive particles and the hardness of the matrix. The cutting performance of dicing blades is very dependent on the material of workpiece. C-dicing blades presents outstanding comprehensive effects with small chips and good self-sharpening properties.

Key words: dicing blade, bonding properties, cutting parameters, cutting force model, preparation

\section{Introduction}

Single crystal $\mathrm{SiC}$, quartz glass, silicon, sapphire and alumina ceramics, with 
outstanding comprehensive properties such as high strength, high hardness, good stability, good wear resistance, are widely used in integrated circuits and other semiconductor fields[1-2]. These applications usually demand to cut off the materials or fabricate micro structure on the surface. Besides electrochemical machining[3], laser beam machining[4], water jet cutting[5], abrasive jet cutting and mechanical cutting[6], Grinding with dicing blade is an very important method to cut and fabricate miro figures on surface of these material [7]. It removes material by scratching workpiece with diamond grits in dicing blades [8].

High cutting quality and high service life are usually the goals pursued in dicing process. However it is a paradox that one dicing blade presents both high cutting quality and high service life due to so complex influence factors including the materials of workpiece, the size and shape of abrasive, the distribution of abrasive size, matrix, the hardness of dicing blade, porosity, the bonding strength of grains and matrix, microstructure of dicing blade and dicing parameters. To improve the cutting properties, four types of dicing blades including metal binder [12], resin binder [9], ceramic binder [11] and electroplated nickel binding agent[10] are usually produced. Hot press sintering technology is the common method to prepare metal binder dicing blade, resin binder dicing blade and ceramic binder dicing blade [18]. It needs to control the sintering temperature, pressure and the component of powder to obtain the dicing blade with good cutting properties. Recently spark plasma sintering [19] is developed to obtain well-distributed metal dicing blade by using low processing temperature and short sintering time. Besides hot press sintering [13], UV curing technology is also used to prepare resin binder dicing blade [14]. It converses liquid resin to solid resin by absorbing a certain range of ultraviolet light [15]. Electroplated nickel binder dicing blade is mainly produced by plating an ultra-thin metal film on the surface of the metal substrate to fix diamond grits through the electroplating method. The method is easy to produce nodulation phenomenon and contains magnetic impurities and other defects [16]. Resin binder dicing blade possess good sharpness, better toughness and lower cost. But it has the disadvantages of short service life and low strength [20]. Electroplated nickel binder dicing blade with 
30 100 $\mu \mathrm{m}$ thickness can produces few cutting damages and low cutting heat [21], but the production process needs to be improved. Ceramic binder dicing blade has high strength, high wear resistance and high service life, but the poor self-sharpness and cutting quality limit its application in the cutting of soft and brittle material [20]. Metal binder dicing blade, with good rigidity, moderate matrix hardness, high service life and high sharpness, has good comprehensive performance [22]. It is often used in semiconductor packaging to provide technical support for chip cutting and processing.

No matter which types of dicing blades, the bonding strength of diamond grits and matrix is the key factor to influence the cutting quality and service life. It not only determines the difficulty of diamond grits falls off from the dicing blades, but also sets a maximum value for the cutting force of diamond grits acted on workpiece. Therefore the cutting damages are limited in a certain range. In order to contribute to findings about the bonding properties of diamond grits and matrix on performance of applied bonds in dicing blades, this work aims to develop three kinds of dicing blade with different components and compare their cutting properties on quartz glass and $\mathrm{SiC}$ by observing the spindle current value of cutting machine, the radial grinding force of dicing blade, the radial wear amount of dicing blade and the edge collapse size of workpiece. It also proposes a grinding force model and quantitative analysis the tool deviation coefficient of the three dicing blade.

\section{Elemental analysis and preparation methods of ultra-thin dicing blade}

\subsection{Elemental analysis of dicing blade}

Although dicing blade is a thin grinding wheel with a thickness of $50 \sim 200 \mu \mathrm{m}$ and a diameter of about $58 \mathrm{~mm}$, its preparation involves many factors and the interaction between these factors. High-quality dicing process should carefully considers many factors, such as the purity of raw materials, the interaction between various components, the mixing uniformity of powder, the spreading uniformity of 
diamond grits, reasonable sintering temperature, the thinning method of dicing blade, the precision finishing of inner hole and outer circle, optimized dicing parameters and precision dicing machine. Among these factors, the components and their interaction have an important impact on the performance of dicing blade. In order to investigate the interaction mechanism of each component, this study classifies the components into about eight aspects of sharpening element, strengthening element, supporting element, combination element, wear resistance element, reductant element, toughening element and moistening element as shown in Fig.1. Diamond grits and matrix combination are the basic essential components of dicing blades. The common matrix is copper-tin alloy, copper-tin-cobalt alloy, copper-tin-titanium alloy and copper-tin-zinc alloy $[23,24]$. These matrix are difficult to bond with diamond grits, which can lead to the low service life of dicing blade. It needs coating some supporting metal such as iron, cobalt, tungsten, nickel, titanium on diamond grits to increase the bonding strength between diamond grits and matrix because these metals are easy to react with diamond in high sintering temperature. The matrix alloys with low melting point such as copper-tin alloy are easy to flow on the high sintering pressure so that the porosity structure is damaged. Therefore some strengthening elements such as silicon carbide particles, alumina particle, CBN particles and carbonyl iron are add to mixed powders to form framework together with diamond grits. Furthermore, sharpening elements such hollow sphere, pore forming agent, hexagonal boron nitride, carbon particles are also used to form porosity structure or weaken structure. So dicing blade presents good self-sharpening performance because the worn diamond grits are easy to fall off from matrix. In addition, in order to adjust the service life of dicing blade, wear resistant elements such zinc-nickel, zinc-cobalt and silicon carbide are introduced into the components of dicing blade. On the process of mixing powders and sintering, metal particles are easy to be oxidized by oxygen or other oxidants, which will increase the brittleness of dicing blade. So a lot of reductant elements such as aluminum, graphite, silicon and boron are used. Sometimes, toughening elements such as rare earth elements, zinc, nickel, silver and moistening elements such as boron, chromium, rare earth elements, titanium are 
introduced to adjust the toughness and the loose structure od dicing blade.

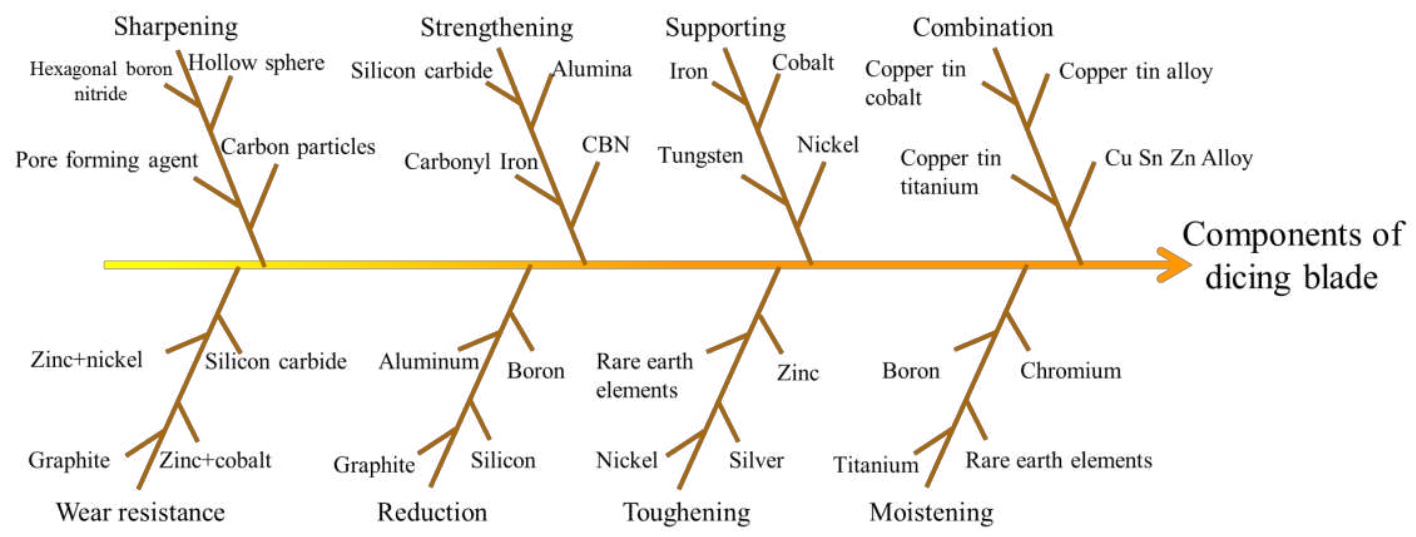

Fig.1 Components of dicing blade

Beside of the components of dicing blade, sintering temperature has important influence on the performance of ultra-thin diamond dicing blade. The carbonization of diamond particles will occurs if the sintering temperature exceeds $800^{\circ} \mathrm{C}$. Too low sintering temperature will lead to low bonding strength between diamond grits and matrix. So the sintering temperature should be finely controlled in order to improve the bonding strength and to avoid diamond particle to be oxidized excessively. It can be adjusted according to different diamond workpiece, grits and components of dicing blade.

\subsection{Components of dicing blade}

Quartz glass and single crystal are difficult-to-cut brittle materials with dicing blade. Chipping and edge collapse are easy to occur during the dicing process. Combined with the above analysis, this study proposed three kinds of dicing blades for cutting difficult-to-cut brittle materials as shown in Table 1. It is easy to cause alloy segregation because the melting point is significantly different between copper and zinc. So in order to compare the influence of components on cutting performance, alloy powder are used instead of elementary substance. 
Table 1. The components of three dicing blades

\begin{tabular}{ccc}
\hline Dicing blade No. & Components of matrix & Mass ratio (\%) \\
\hline A & CuSn33+CuZn20+Co+YA520 & $32 ; 18 ; 20 ; 30$ \\
B & CuSn40+Cu+Sn+CuSn10 & $25 ; 50 ; 5 ; 20$ \\
C & $\mathrm{Cu}+\mathrm{Sn}+\mathrm{Zn}+\mathrm{Ni}$ & $70 ; 18 ; 5 ; 7$ \\
\hline
\end{tabular}

For the dicing blade A, three kinds of alloy powders are used to avoid alloy segregation. CuSn33 is the basic bonding phase and its brittleness allows diamond grits fall off from the matrix. CuZn20 can refine the matrix and enhance the impact resistance of dicing blades. YA520 is a kind of alloy powder, which is used to strengthen the matrix. Co, as skeleton phase, is beneficial to form porosity structure and increase the bonding strength between diamond grits and matrix.

For the dicing blade $\mathrm{B}, \mathrm{CuSn} 40$ and $\mathrm{CuSn} 10$ can improve the brittleness and toughness of the matrix respectively. The introduction of dendrite copper powder and tin is beneficial to the combination of the alloy powders. The melting point of tin is $231.89^{\circ} \mathrm{C}$, which can obviously reduce the sintering temperature of dicing blade. The dissolved melting tin and copper can also reduce the surface tension and internal interfacial tension of the matrix, which can improve the overall fluidity of the matrix.

For the dicing blade $\mathrm{C}$, elemental metals are basic matrix components. Adding appropriate amount of nickel to the low temperature alloy of copper-tin can strengthen the bonding strength between diamond grits and matrix. The introduction of zinc powder is beneficial to improve the toughening and combination performance of dicing blade.

\subsection{Preparation process of dicing blade}

In order to obtain proper and uniform bonding strength between abrasive grits and matrix, well-arranged preparation process is necessary in addition to optimized component. As shown in Fig.2, the prepared metal powders and diamond abrasive were first mixed for 20 minutes in the ball milling machine according the component 
ratio of dicing blade $\mathrm{A}, \mathrm{B}$ and $\mathrm{C}$ respectively. Then the volume of mixed powders was calculated according to the component ratio of different dicing blade and the density of each component. An electronic balance with an accuracy of $0.001 \mathrm{~g}$ was used to measure the mixed powders to fill in graphite mould. Graphite has strong reducibility, it can prevent the mixed metal powder in the high sintering temperature condition from being oxidized. In this filling process, assistant metal mould was also used to control the thickness of spread powders. After filling the mixed powder into the mould, a flat scraper was used to smooth, scrape and remove the redundant mixed powder. The following is forming in the hot press sintering machine.

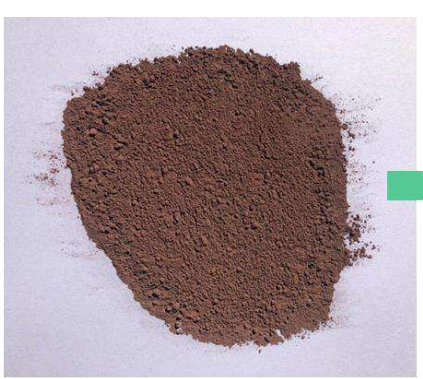

Mixing the powder

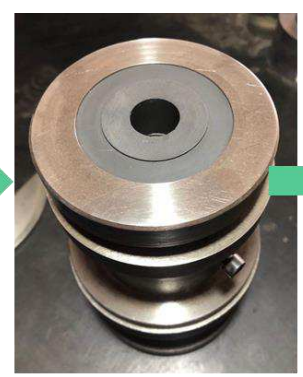

Adjusting the mold

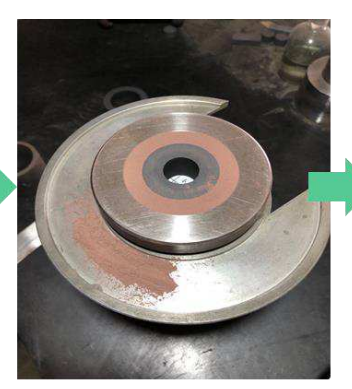

Spreading powder evenly

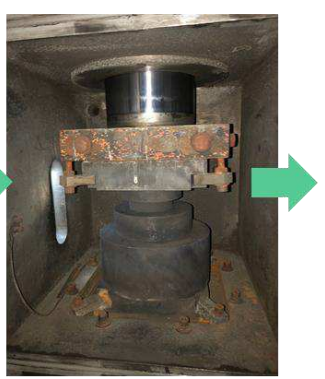

Hotting-press sinter

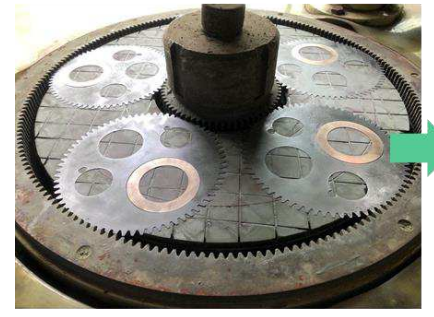

Thinning and lapping

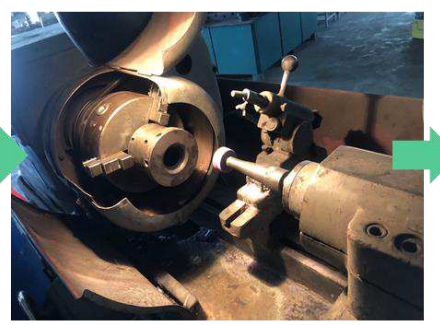

Grinding inner hole

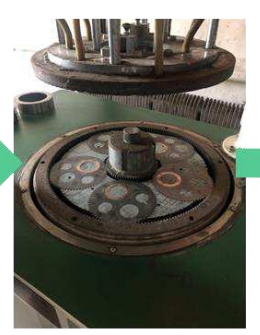

Lapping and sharpening the edge

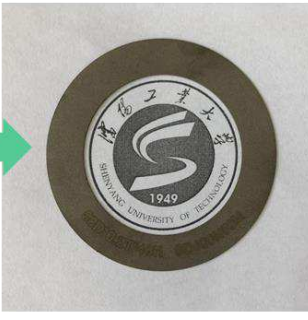

Finishing product

Fig.2 Preparation process of dicing blades

The metal powders of dendritic copper, tin, zinc, nickel, cobalt used in the experiment was selected with a purity of more than $99.9 \%$ and 400 meshes. The components of CuSn33, CuZn20, YA520, CuSn40 and CuSn10 was selected alloy powder with a purity of over $99.9 \%$ and a particle size of 38 to 42 microns. 400 mesh diamond particle was used as abrasive powder as shown in Fig.3. 


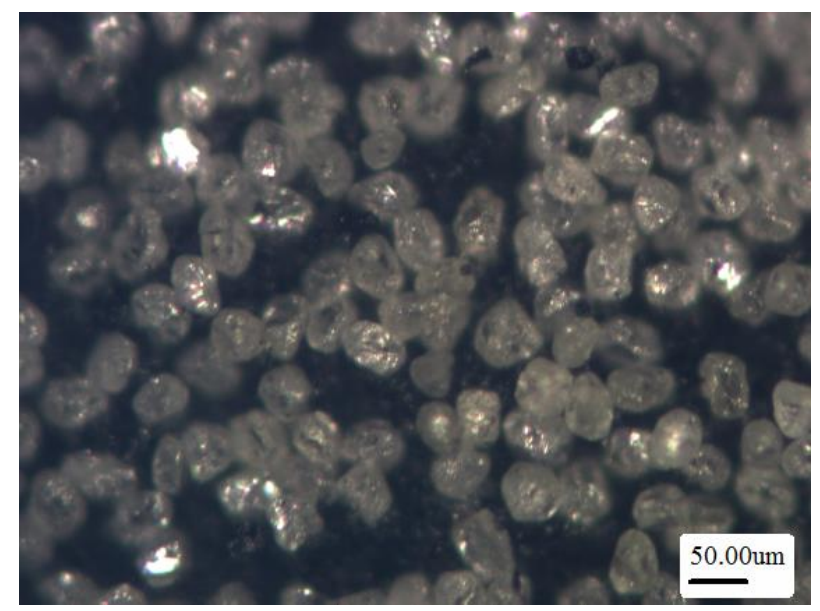

Fig.3 400 mesh diamond particles

Fig.4 shows hot press sintering machine and schematic diagram of sintering process. It needs to be noted that the sintering process should be conducted in the vacuum environment because the dicing blade is easily oxidized in the sintering process. The particle of metal powder is small after the ball milling process. So the metal particle is easy to absorb vapor or oxygen. These absorbed vapor and oxygen need to desorb from the surface of metal particles by elevating temperature or vacuuming. As shown in Fig.5, in the sintering process the temperature was elevated to about $400^{\circ} \mathrm{C}$ and maintains for three minutes in order that the melted tin diffuse into other metal alloy. The maximum temperature of three dicing blades were different because there are different components in each dicing blades.

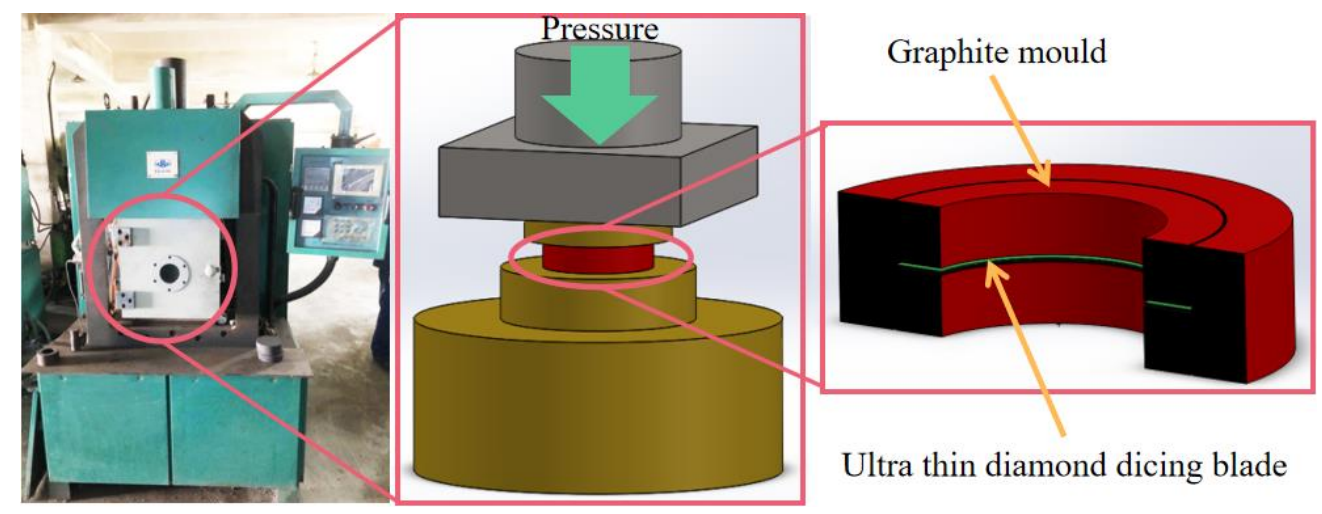

Fig.4 Hot press sintering machine and schematic diagram of sintering process 


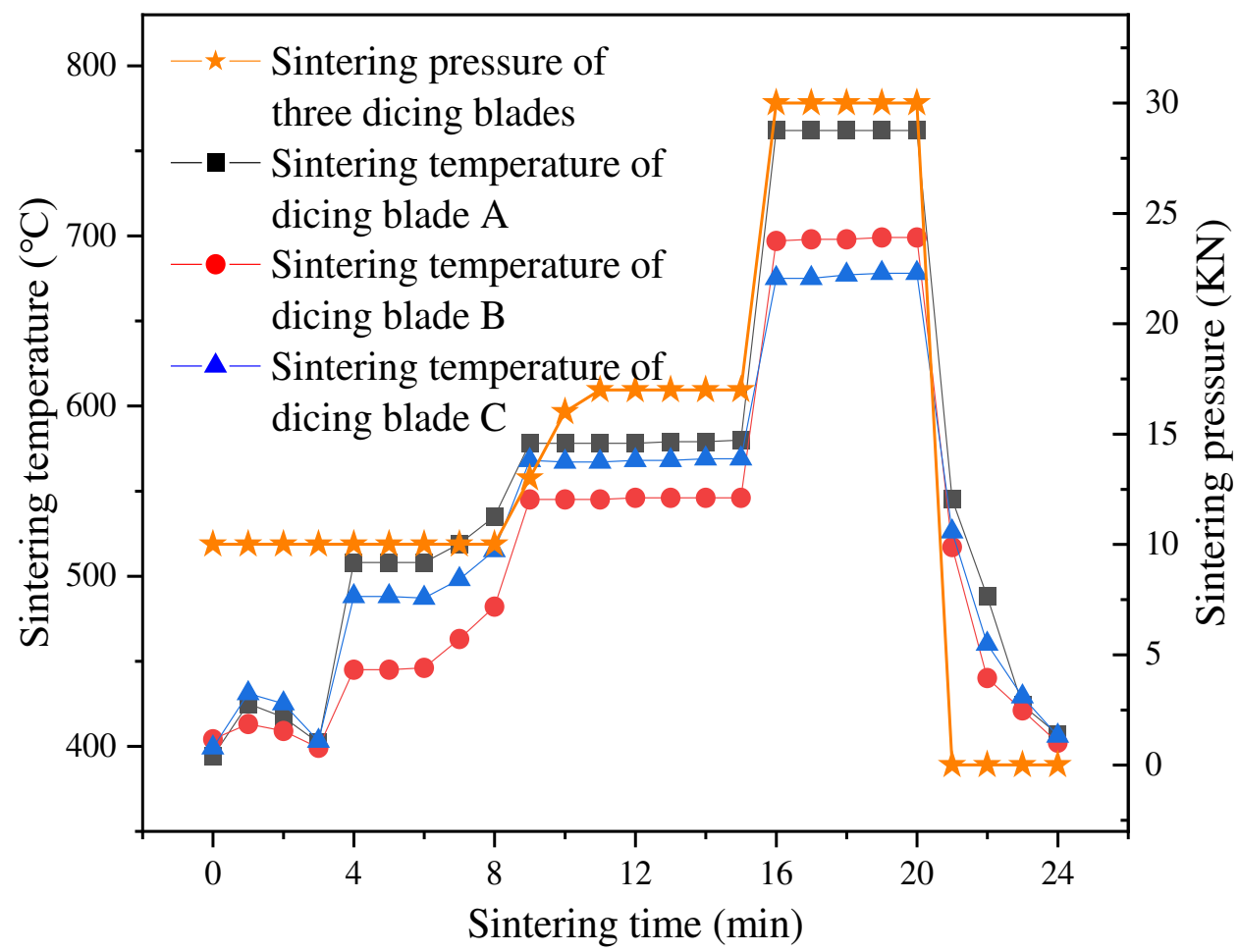

Fig.5 Hot pressing sintering temperature and pressure curve of dicing blades

There is a significant difference of thermal expansion coefficient between the sintered dicing blade and graphite mould. The heating process is divided into three stages: transition stage, low-temperature alloying stage and insulation stage. The most important one is the low-temperature alloying stage. The temperature in this stage is usually controlled between $500 \sim 580^{\circ} \mathrm{C}$ because the low-temperature metal spreads a lot around at this time. Just as the tin element in the above formula connects copper and other elements and produces alloy reaction at this stage. The final holding time should not be too long. With the increase of holding time, the alloying enrichment area of the cutting sheet will greatly increase, resulting in excessive hardness of the matrix and affecting the machining accuracy.

The dicing blade is squeezed by the inner core during the temperature dropping process. So in order to prevent the break of dicing blade, the inner core should be quickly taken out from the furnace with a copper rod when the temperature drops below $400^{\circ} \mathrm{C}$. 
In addition, the pressure value during hot pressing sintering shall be continuously adjusted with the three heating stages, starting from the pressure of $10 \mathrm{kN}$ in the transition stage, and then gradually increasing the pressure value in the low-temperature alloying stage until the pressure value reaches the maximum $30 \mathrm{KN}$ in the insulation stage.

After the sintering process, the rough grinding and thinning process were conducted by using 800 mesh $\mathrm{SiC}$ abrasive in double surface lapping machine. Then the dicing blade was placed in a special fixture to trim the roundness and the inner hole to meet the concentricity requirements. Finally, a cast iron disc was used to finely lap and sharpen the dicing blade. During this process, a small amount of surface bonding agent was removed to increase the exposure of the diamond grits. Therefore, an ultra-thin diamond dicing blade with an outer diameter of $58 \mathrm{~mm}$, an inner diameter of $40 \mathrm{~mm}$, and a thickness of $200 \pm 5 \mu \mathrm{m}$ was prepared through the above-mentioned process.

In order to characterize the performance of the prepared dicing blades, the dicing experiments were conducted on the DS610 dicing machine produced by Heyan Technology Corporation Limited Company as shown in Fig.6. In the cutting process, the spindle current and grinding force was recorded. The surface morphology and chipping damage of dicing blade were also observed after the cutting experiment.

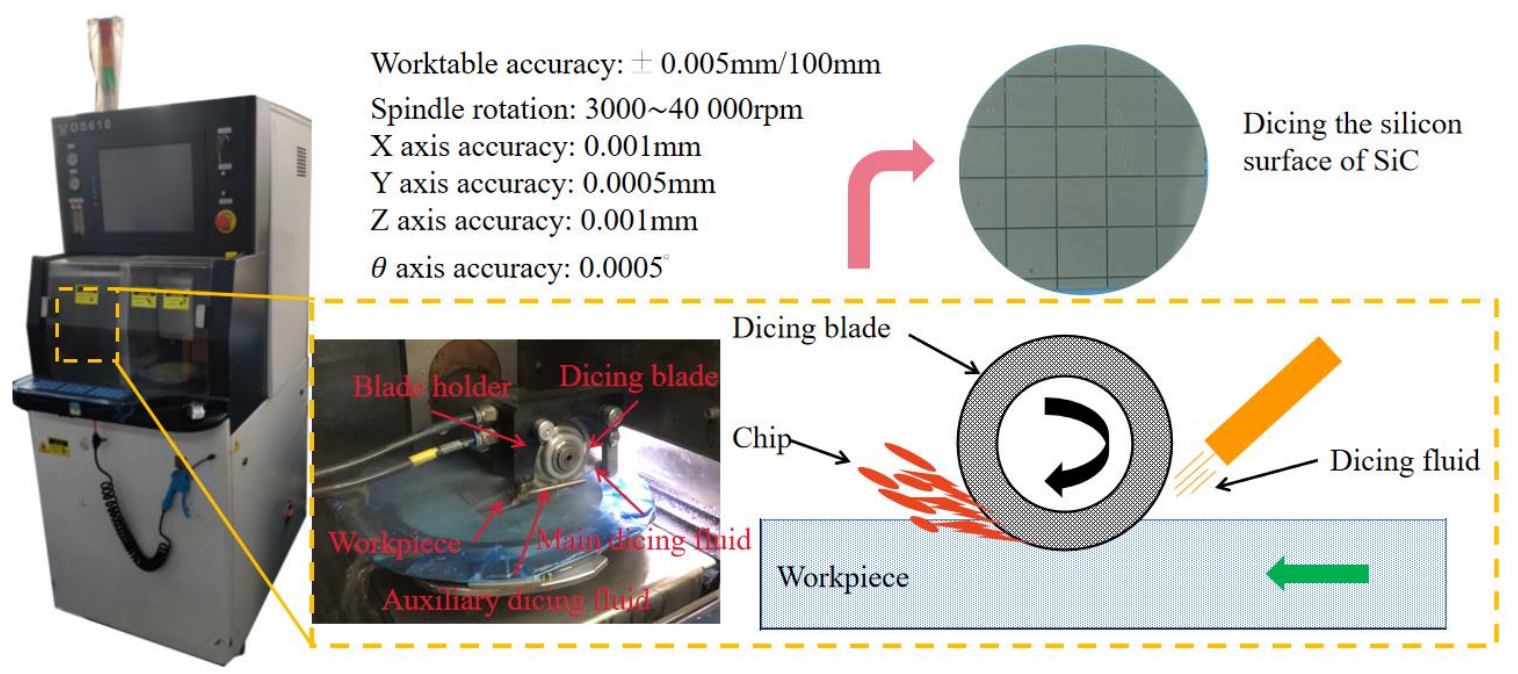

Fig.6 Dicing machine and parameters 


\section{Grinding force prediction of dicing blade}

\subsection{The sharpness of diamond grits on dicing blade}

Grinding force can reflect the interaction between diamond grits and workpiece. Large grinding force of diamond grits not only can cause obvious damages to workpiece, but also can promote diamond grits to fall off from dicing blade. High cutting quality requires uniform grinding force. The height and distribution of exposed diamond grits on the surface of dicing blade can influence the grinding force. After the sintering process, the dicing blades are sharpened on the lapping plate by $\mathrm{SiC}$ abrasive to exposed diamond grits. The soft matrix is easy removed from the surface of dicing blades. Therefore, the number of exposed diamond grits is more than that of dicing blades with hard matrix. As seen from Fig.7, the exposed diamond grits of dicing blade $\mathrm{C}$ are more than dicing blade $\mathrm{A}$ and dicing blade $\mathrm{B}$. Comparing the components of three dicing blade, it is easy to find that elementary powders is the main component of dicing blade $\mathrm{C}$. The main components of dicing blade $\mathrm{A}$ and $\mathrm{B}$ are alloy powder. The hardness of alloy powders is large than that of elementary powders. So it is difficult for the matrix of dicing blade A to remove to expose the diamond grits. The grinding force with dicing blade $\mathrm{C}$ will smaller than that of other two dicing blades. Dicing blade $\mathrm{C}$ will has better self-sharpening ability in dicing process.

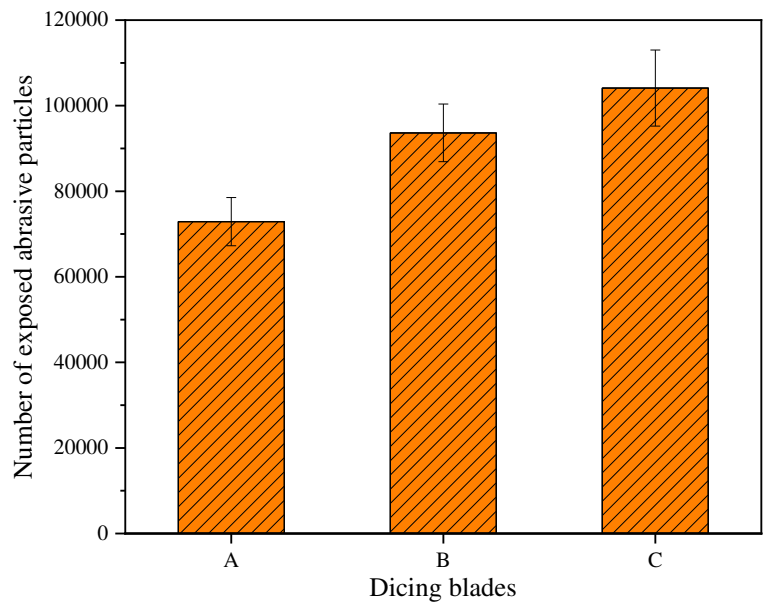

Fig.7 The exposed abrasive grit number of different dicing blades 


\subsection{Deviation coefficient of different dicing blades}

Due to the different toughness, the dicing blades are easy to produce a certain offset distance in the cutting tiny gap. Here this study defines the deviation coefficient $\gamma$ as the relative difference of the actual cutting width $T_{\mathrm{r}}$ and the thickness $b$ of dicing blade as shown in Fig.8.

$$
\gamma=\frac{T_{r}-b}{b}
$$

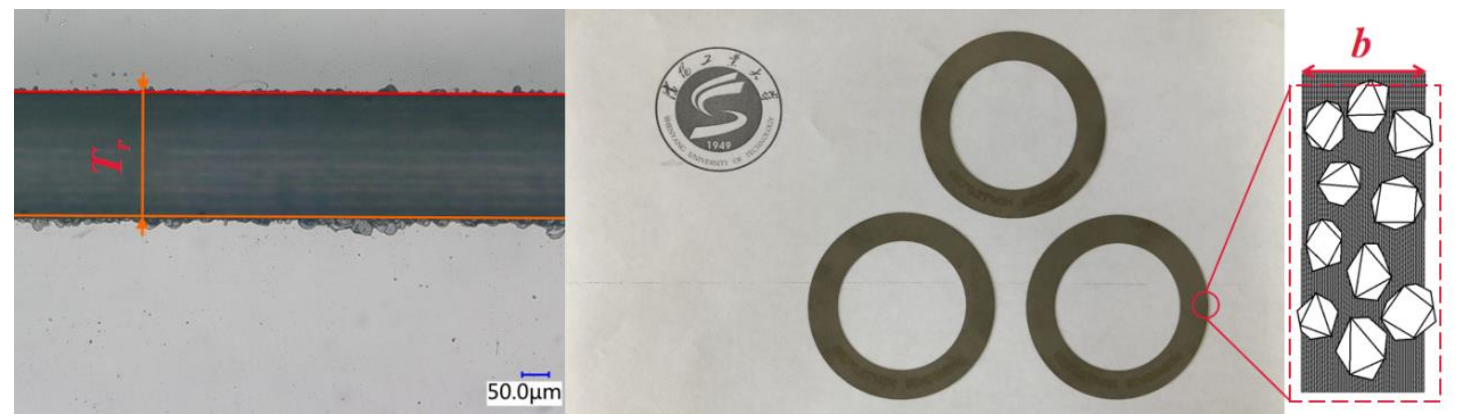

Fig.8 Relationship between the actual dicing distance and the thickness of quartz slice.

From above analysis, the dicing blade with high toughness has small deviation coefficient because it is difficult to deform under the interaction of cutting force. Fig.9 presents the deviation coefficient of different dicing blades. It can be seen from the figure, the dicing blade A possesses a small deviation coefficient due to its high hardness of matrix. The bonding matrix containing a variety of alloys increases significantly the strength of dicing blade. It is difficult for the dicing blade A to deform in cutting process. On the contrary, the dicing blade $\mathrm{C}$ prepared by elementary powders has large deviation coefficient due to its deformation in dicing process. In addition, the dicing blade presents different deviation coefficients when cutting different materials. According to the experimental results, the deviation coefficients when cutting $\mathrm{SiC}$ material is larger than that of cutting quartz glass. The main reason causing the results may be that the larger grinding force increase the deformation of dicing blade when cutting hard material. So the deviation coefficient of dicing blade should be included during calculating the cutting width with dicing blade accurately. 


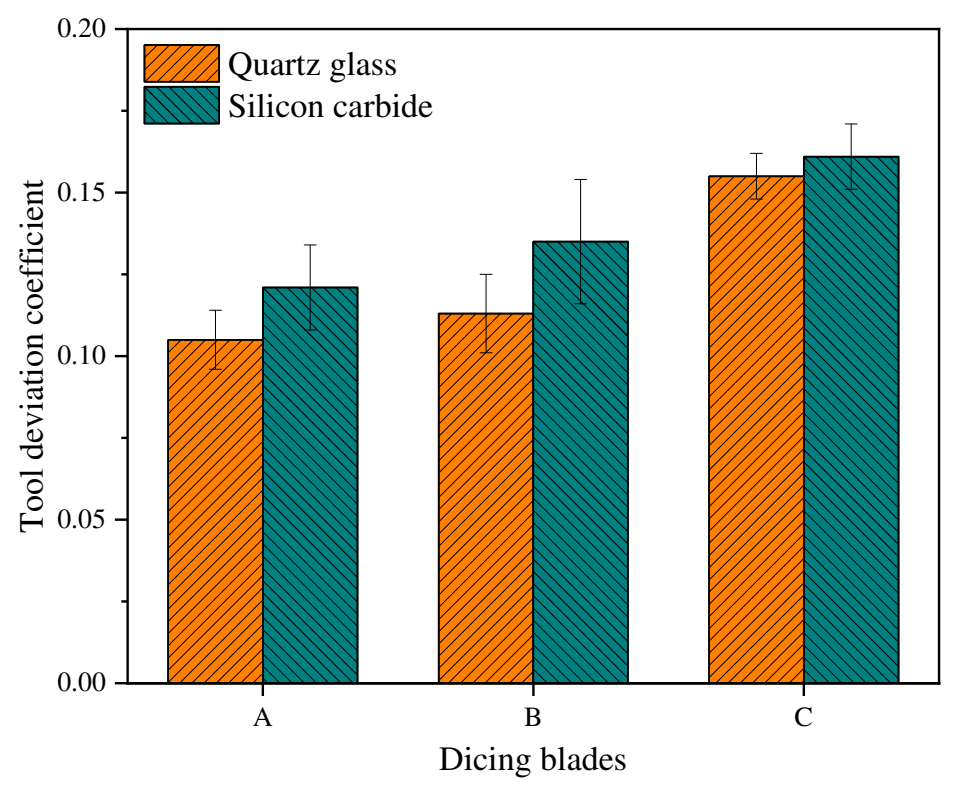

Fig.9. Deviation coefficients of different dicing blades.

\subsection{Prediction of grinding force with dicing blade}

We can use the deviation coefficient defined as above section to calculate the grinding force of a single diamond grit. In this study, the diamond grits were assumed to have a certain apex angle of $2 \alpha$. Then the tangential $F_{\mathrm{tp}}$ and radial grinding force $F_{\text {np }}$ of single diamond grit can be established as following[23],

$$
\begin{gathered}
F_{t p}=\frac{\pi}{4} F_{p} \tau_{p}^{2} \gamma \sin \alpha \\
F_{n p}=F_{p} \tau_{p}^{2} \gamma \sin \alpha \tan \alpha
\end{gathered}
$$

Where, $F_{t p}$ and $F_{n p}$ are the grinding forces of the abrasive particles in the tangential and radial directions, respectively, $\tau_{p}$ is the average exposed height of the abrasive grits [26], as shown in Fig.10. 


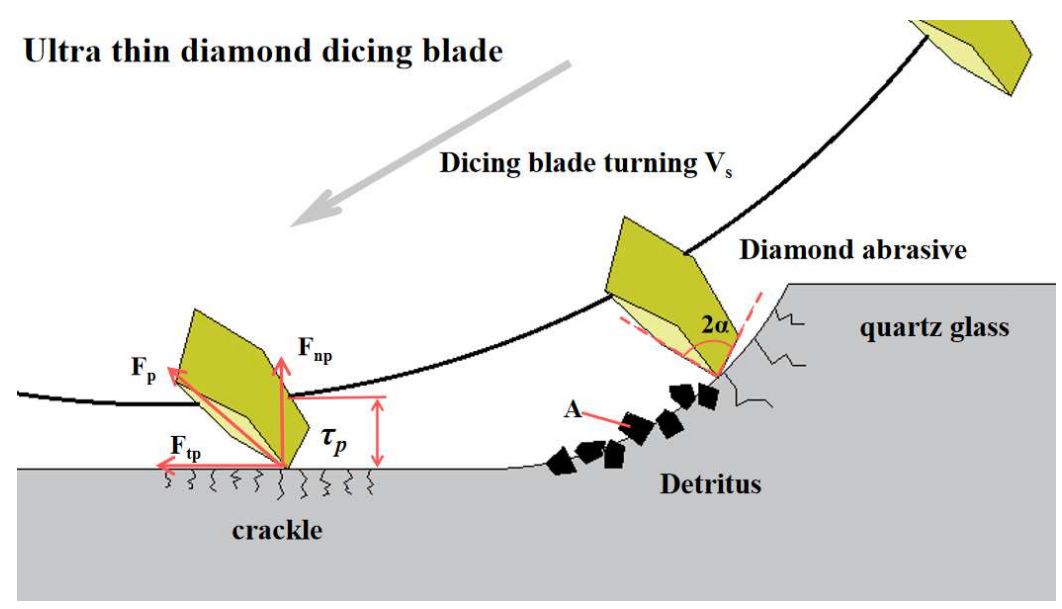

Fig.10.Schematic diagram of diamond grit acting on workpiece

According to Newton's third law, the tangential force $F^{\prime}{ }_{t p}$ acting on the chip breaking from workpiece is equal to the grinding force $F_{\mathrm{p}}$ of single grit[27],

$$
F_{t p}^{\prime}=F_{p}=\frac{6}{\pi \cos \alpha} F_{p}^{\prime}
$$

According to the failure criterion of brittle materials, the tangential force $F^{\prime}$ tp can be expressed as [28],

$$
F_{p}^{\prime}=k A^{-\varepsilon}
$$

In the equation, $k$ is the hardness coefficient of workpiece material; $A$ is the chip breaking area. Combining the above equations, the tangential and radial grinding force of single diamond grit can be deduces as,

$$
\begin{array}{r}
F_{t p}=\frac{3}{2 \cos \alpha} k A^{-\varepsilon} \tau_{p}^{2} \sin \alpha \\
F_{n p}=\frac{6}{\pi} k A^{-\varepsilon} \tau_{p}^{2} \tan ^{2} \alpha
\end{array}
$$

According to the width $b$ of dicing blade, the number of abrasive grits per unit area $N_{p}$ and the speed of dicing blade $V_{\mathrm{s}}$, the number of abrasive grits $N$ participating in cutting of the dicing blade is calculated as,

$$
N=\gamma \tau_{p} b N_{p} V_{s}
$$

Finally, the total tangential and radial grinding forces of the dicing blade can be expressed as,

$$
\begin{gathered}
F_{t z}=\frac{3}{2} k A^{-\varepsilon} \tau_{p}^{3} \gamma b N_{p} V_{s} \tan \alpha \\
F_{n z}=\frac{6}{\pi} k A^{-\varepsilon} \tau_{p}^{3} \gamma b N_{p} V_{s} \tan ^{2} \alpha
\end{gathered}
$$




\section{Experimental results and discussion}

\subsection{Influence of different feed rate on spindle current with three dicing blades}

The spindle current can intuitively reflect the grinding force and the sharpeness of dicing blade. This study analysis the cutting performance of three dicing blades by observing the spindle current values during cutting quartz glass and $\mathrm{SiC}$ with different dicing parameters. The cutting experiments were conducted with the spindle rotation speed of $20000 \mathrm{rpm}$, the cutting depth of $0.5 \mathrm{~mm}$, and the feed rates of $2 \mathrm{~mm} / \mathrm{s}, 4 \mathrm{~mm} / \mathrm{s}$, and $6 \mathrm{~mm} / \mathrm{s}$.

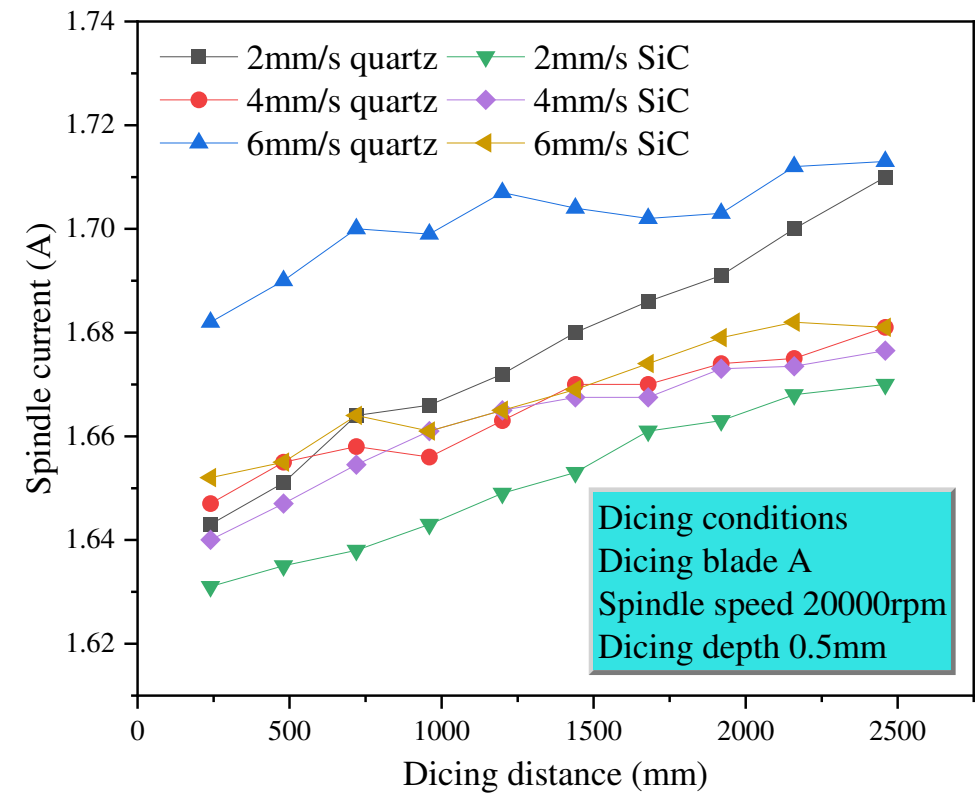

Fig.11. Spindle current varying with the dicing distance and the feed rates when cutting the dicing blade A

As is indicated in the Fig.11, it can be seen that the spindle current value when cutting quartz glass is higher than that of single crystal $\mathrm{SiC}$ material. Since quartz glass with high brittleness is more difficult to cut than SiC material. More hard and brittle chips are produced during cutting process, which has a certain hindering effect on the feed force of dicing blade. The spindle current presents the smallest value 
overall when cutting $\mathrm{SiC}$ material with the feed rate of $4 \mathrm{~mm} / \mathrm{s}$. It indicates that the cutting force with low feed rate is small when cutting the $\mathrm{SiC}$ material. But the spindle current value at $6 \mathrm{~mm} / \mathrm{s}$ is higher than the other two cases, and the fluctuation is the largest at this time. It can be inferred that the chip broken and the falling of diamond grits exist in this process. In addition, the cutting current values remain relatively stable when cutting $\mathrm{SiC}$ at feed speeds of $4 \mathrm{~mm} / \mathrm{s}$ and $6 \mathrm{~mm} / \mathrm{s}$. When cutting quartz glass and $\mathrm{SiC}$, the current values have an obvious increase at the feed rate of $2 \mathrm{~mm} / \mathrm{s}$. It shows that the dicing blade becomes wear at this feed rate. The worn diamond grits decrease the sharpness of dicing blade.

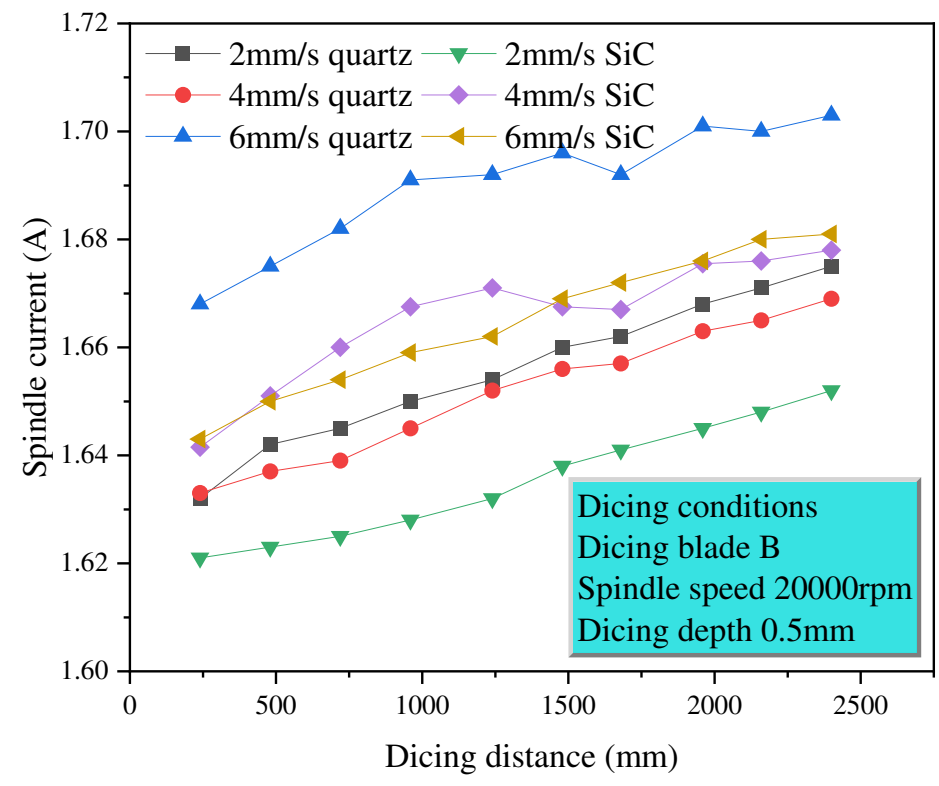

Fig.12. Spindle current varying with the dicing distance and the feed rates when cutting with dicing blade $\mathrm{B}$

As can be seen from the Fig.12, all cutting current increases with the dicing distance, which indicates that the wear of dicing blade occurs in dicing process. In addition, the spindle currents at the feed rate of $6 \mathrm{~mm} / \mathrm{s}$ when cutting quartz glass is obviously higher than that of other conditions. It shows that the dicing blades are easier to wear under the large feed rate. Diamond grits and chips particles break from dicing blade and workpiece respectively. As a result, the hardness of dicing blade does not match the feed rate and the workpiece materials at this condition. Similar with 
dicing blade A, the smallest spindle current occurs when SiC is cut with dicing blade $\mathrm{B}$ at feed rate of $2 \mathrm{~mm} / \mathrm{s}$. It can be deduced that the bonding property and the exposed extent of diamond grits should match the requirements of different workpiece materials. Dicing blades A and B are suitable to cut SiC material.

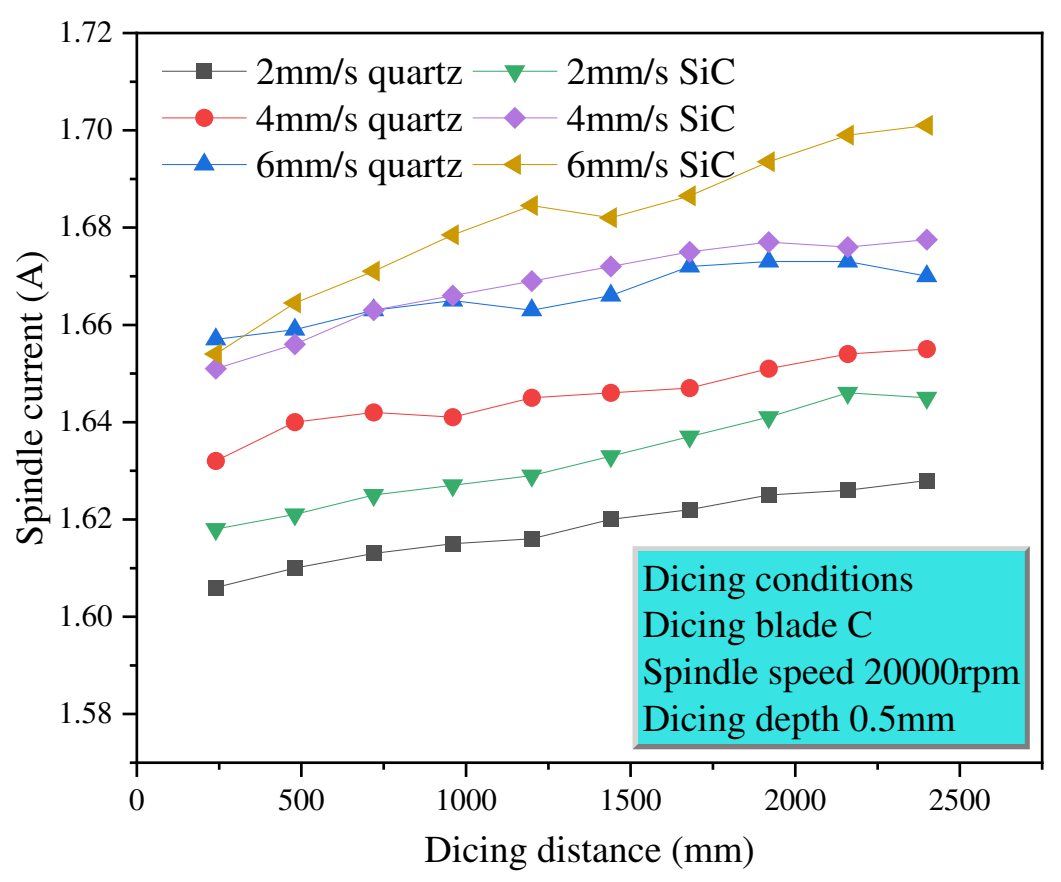

Fig.13. Spindle current varying with the dicing distance and the feed rate when cutting with dicing blade C.

As noted in Figure Fig.13, the dicing blade C prepared with elemental metals has lower spindle current when cutting quartz glass than $\mathrm{SiC}$ material. It means that dicing blade $\mathrm{C}$ with low bonding strength is more suitable to cut quartz glass than dicing blades A and B. Dicing blades A and B have advantages to cut SiC material. It includes that the dicing blade with high bonding strength is fit for the materials with high hardness. It can also be clearly observed from the figure that the overall current value at $2 \mathrm{~mm} / \mathrm{s}$ is significantly lower than the current value in other cases. This is due to the lower bond between the elemental metal and the diamond grits, ensuring the sharpeness and lower cutting force at low feed rate. In addition, it can be observed that the overall current distribution is relatively uniform, indicating that there is no passivation of abrasive particles during cutting. 


\subsection{The influence of bonding property on grinding force}

To quantify the grinding force when cutting with three dicing blades, the grinding force measurement system was fixed on the dicing machine as shown in Fig.14. A force sensor was placed between the vacuum chuck and the quartz glass. Then the force signals in $\mathrm{X}, \mathrm{Y}$, and $\mathrm{Z}$ directions were transmit to computer through the analog transmitter and the signal acquisition card.

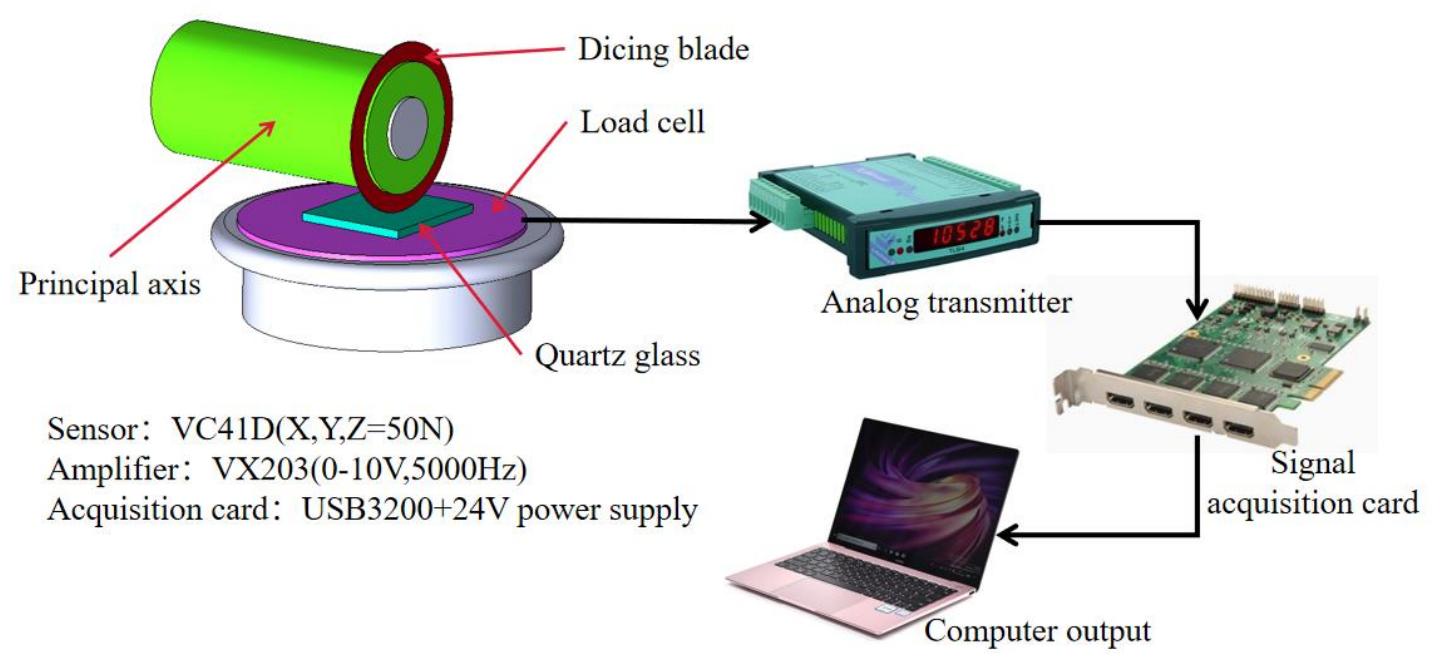

Fig.14.Schematic diagram of grinding force measuring system

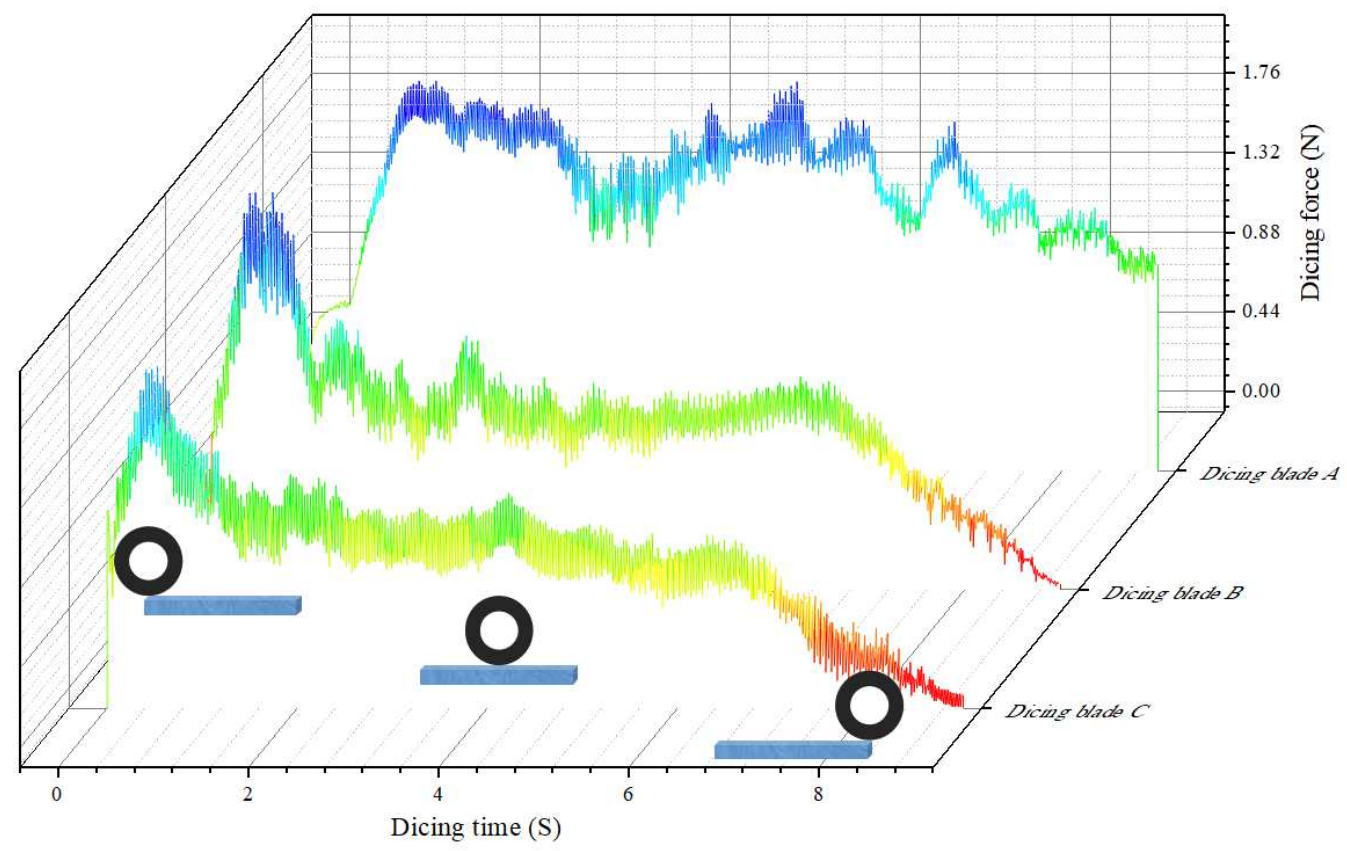

Fig.15. Radial force grinding force of three dicing blades

As can be seen from Fig.15, dicing blade $\mathrm{C}$ has the smallest radial grinding force when cutting the quartz glass due to its best sharpness. Among three dicing blades, the 
cutting force of dicing blade A has a sharp increase and maintains a larger level in dicing process because the poor exposure extent of diamond grits results in the rubbing between the matrix and the quartz debris. And dicing blade A prepared with alloy powders is not easy to achieve self-sharpness during the dicing process. The dicing blade B contains elementary metal powders and alloy powders. The medium bonding strength makes dicing blade B possess a comprehensive performance. The above analysis results also verify the trend of the spindle current along with different dicing blades.

According to the equations (9) and (10), the tangential and radial grinding forces of the dicing blade can be calculated if the parameters of grinding apex angle 2 $\alpha$ [29], speed $V_{S}$, dicing blade width $b$, the exposed height of abrasive grits $\tau_{p}$ are determined. Here the apex angle $2 \alpha$ is assumed as $60^{\circ}$. The speed $V_{S}$, dicing blade width $b$, exposed height of abrasive grits $\tau_{p}$ are obtained according the parameters of cutting and dicing blades. Therefore the predicted grinding force can be calculated and is shown in Fig. 16 together with the experimental results.

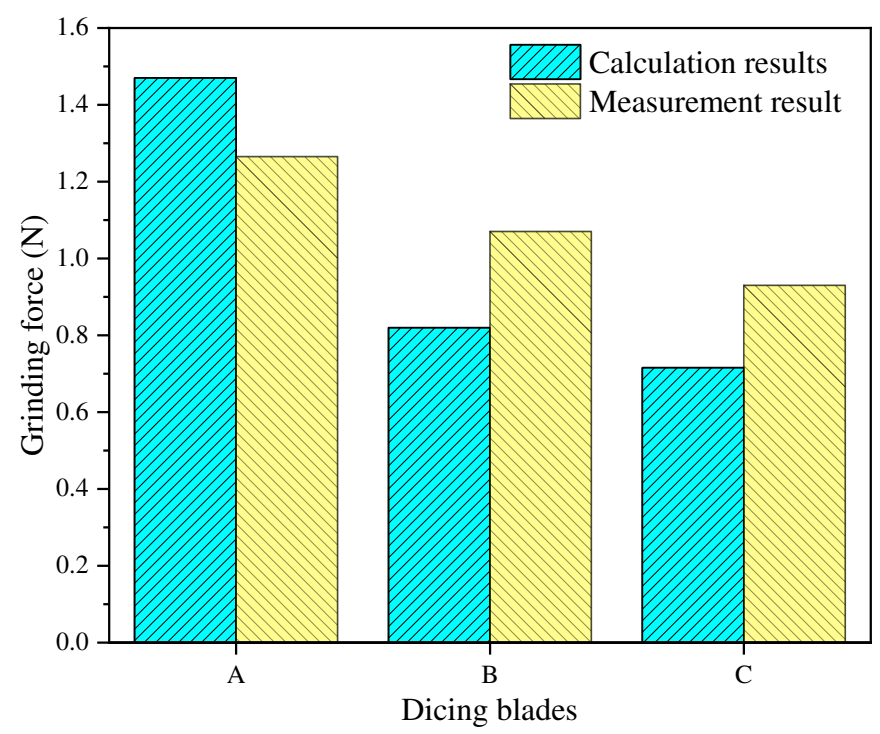

Fig.16. Comparison of predicted grinding force and experimental for results

As can be seen from Fig.16, the tendency of predicted grinding force is consistent with the experimental results when cutting quartz glass with three dicing blade. Meanwhile, the tendency of grinding force is contrary to the deviation 
coefficient $\gamma$ of dicing blade. It also finds that the actual measured result of grinding force when cutting with dicing blade $\mathrm{A}$ is higher than expected value, because the high hardness of matrix in dicing blade decreases the self-sharpening ability of diamond grits. The low exposed extent of diamond grits results the large grinding force due to the poor cutting ability of diamond grits.

\subsection{The influence of bonding property on chipping of cutting edge}

Chipping is the common damage of workpiece during the dicing blade. Both the size and the number of chips on the cutting edge of workpiece can be used to characterize the cutting quality of dicing blade. They are affected by the cutting tool parameters and measured area. In order to qualify the cutting damage conveniently and accurately, this study proposes a unit chipping coefficient $\mu$ by using pixel method. As indicated in Fig.17, the method selects randomly 10 measurement area to extract the chipping area by calculating the pixel value. Therefore, the unit chipping coefficient $\mu$ is defined as following equation.

$$
\mu=\frac{\frac{w}{a^{2}}-c \times b(\gamma+1)}{\beta \times c}
$$

Where, the resolution $a$ is 72 pixels per inch. $w$ is the total measured pixel value, $b$ is the thickness of cut sheet, $c$ is the cutting length, and $\beta$ is the maximum chipping width.
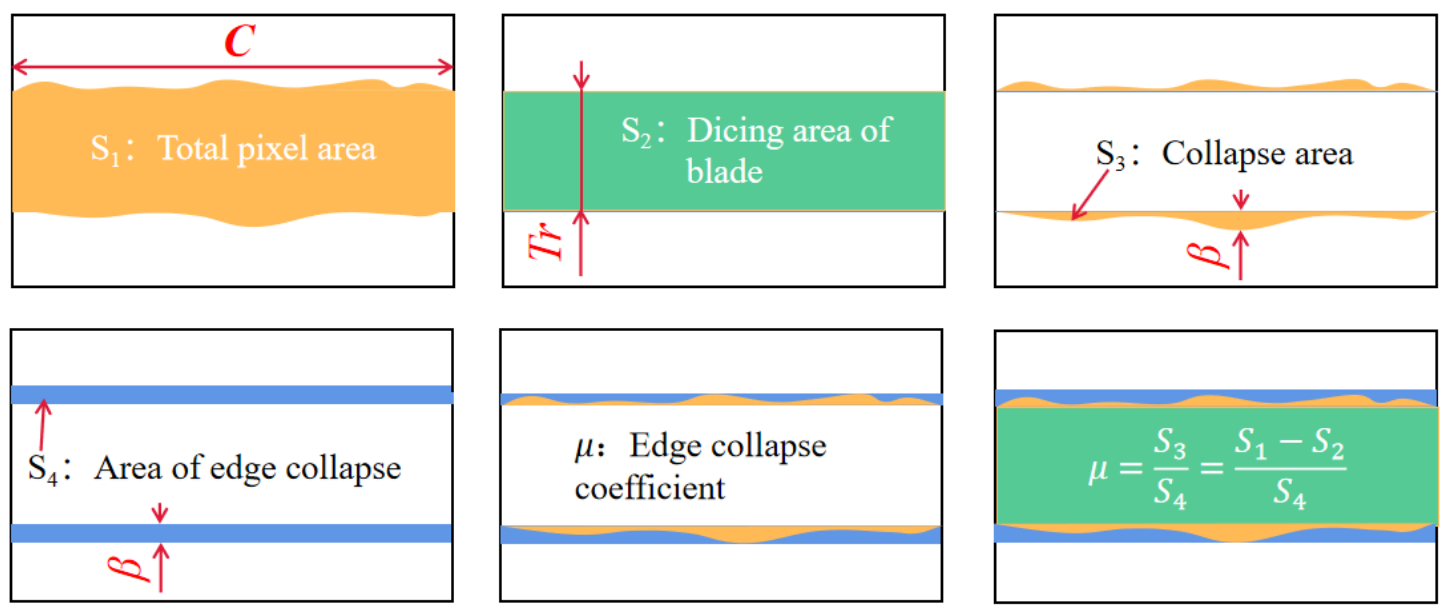

Fig.17. Calculation method of edge collapse coefficient. 
According to the equation (11), the unit chipping coefficients of quartz glass and $\mathrm{SiC}$ diced with different parameters are calculated by analyzing the morphology of cutting edge. Fig.18 shows the unit chipping coefficients of quartz glass and $\mathrm{SiC}$ cut with different dicing blades. As can be seen from the figure that the overall chipping effect of quartz glass is higher than that of $\mathrm{SiC}$. It means that quartz glass is difficult to cut than $\mathrm{SiC}$ although its harness is lower than $\mathrm{SiC}$. The reason to cause the serious chipping may attribute to the high brittleness and the low strength of quartz glass. Dicing blade A produces more serous edge chipping overall than that of dicing blades $\mathrm{B}$ and $\mathrm{C}$. It reveals that dicing blade $\mathrm{A}$ is not suitable for cutting quartz glass due to its high bonding strength. Because dicing blade A prepared with three alloy materials has high hardness, it is more suitable to cut ceramic materials. Dicing blade $\mathrm{C}$ has lower bonding strength due to the elementary introduced in sintering process. It produces less edge chips that other dicing blades. Especially in the feed rate of $6 \mathrm{~mm} / \mathrm{s}$, the chipping coefficient is obvious smaller than other condition during cutting quartz glass. It indicates that the feed rate should also match the bonding strength of dicing blades. The dicing blade with a certain bonding strength should be used in a certain condition of cutting parameters.

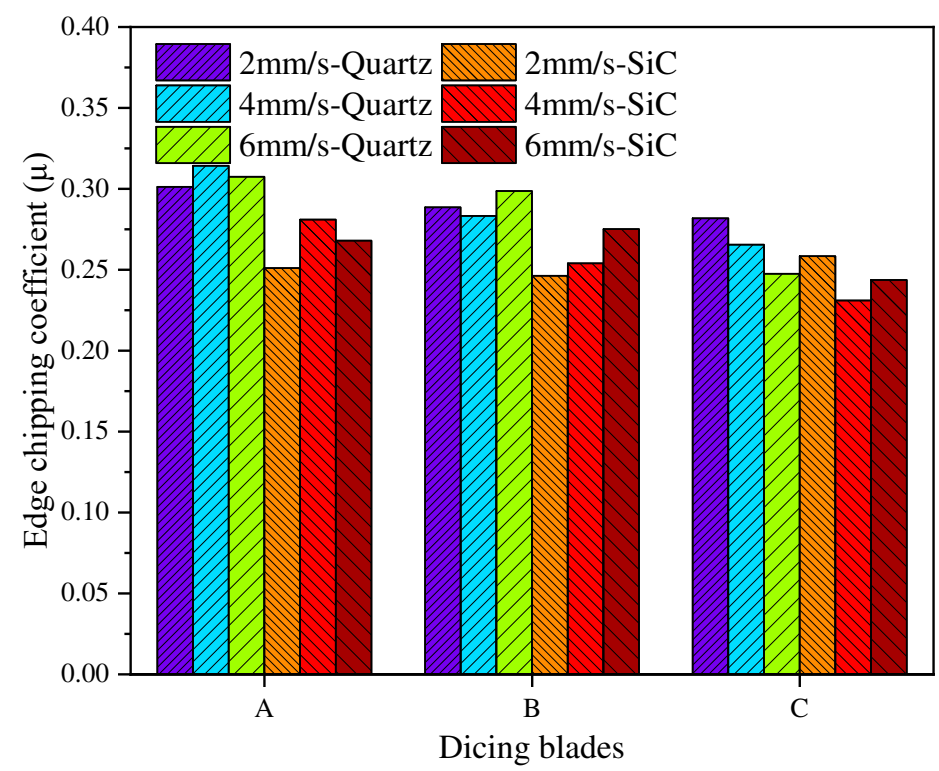

Fig.18. Unit chipping coefficients of different dicing blades when cutting quartz glass and $\mathrm{SiC}$ 


\subsection{Tool wear of three dicing blades}

Tool wear is an important factor to characterize dicing blade. It is usually related to the bonding strength of dicing blade, the material of workpiece and the cutting parameters. The tool wear amount of dicing blade can be obtained by tool setting in machine before and after dicing process. In order to ensure the reliability of tool wear measurement, the cutting distance and the cutting depth were set at $2400 \mathrm{~mm}$ and $0.5 \mathrm{~mm}$ respectively.

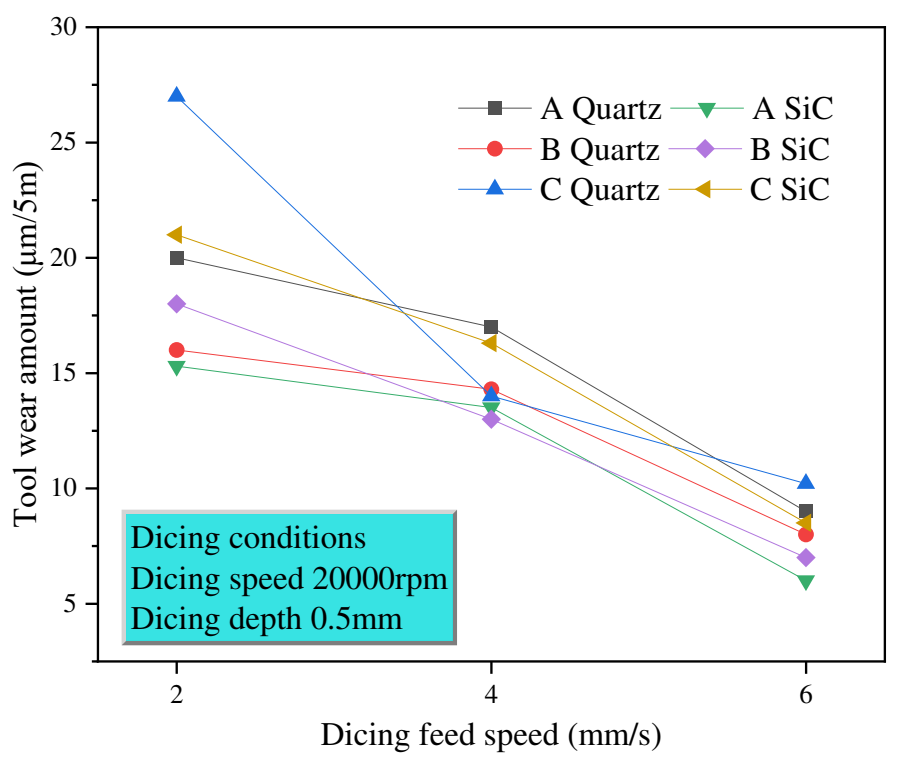

Fig.19. Tool wear amount of three dicing blades in different cutting parameters

Fig.19 shows the tool wear amount of three dicing blades in different cutting parameters. As can be seen from the figure, when cutting speed is 20000rpm, the feed rate is inversely proportional to the overall tendency of tool wear amount. All dicing blades have lower tool wear amount at the feed rate of $6 \mathrm{~mm} / \mathrm{s}$ although the grinding force is large in this cutting condition. The reason to cause this result can be that the cutting time is shorten at high feed rate. Among the three dicing blades, dicing blade A presents the smallest wear amount when cutting $\mathrm{SiC}$ at feed rate of $6 \mathrm{~mm} / \mathrm{s}$, indicating that dicing blade A with high bonding strength and poor self-sharpening ability is suitable to dicing the hard material of $\mathrm{SiC}$ in high feed rate of $6 \mathrm{~mm} / \mathrm{s}$. Dicing blade $\mathrm{C}$ with low bonding strength guarantees its better edge chipping effect, but it 
has more serious tool wear comparing with other dicing blades. Dicing blade B prepared with elementary metal powder and alloy powder has a moderate tool wear amount, indicating that the tool wear amount has significant relationship with the bonding strength or the hardness of dicing blade. If arranging the experiments in order of the chipping coefficient from small to large, the tool wear amount of dicing blades are summarized as shown in Table 2.

Table 2. Tool wear amount of dicing blades in order of the chipping coefficient from small to large

\begin{tabular}{cccccc}
\hline No. & Dicing blade & Feed rate & $\begin{array}{c}\text { material of } \\
\text { workpiece }\end{array}$ & $\begin{array}{c}\text { tool wear } \\
\text { amount }\end{array}$ & $\begin{array}{c}\text { Edge collapse } \\
\text { coefficient }(\mu)\end{array}$ \\
1 & $\mathrm{C}$ & $4 \mathrm{~mm} / \mathrm{s}$ & $\mathrm{SiC}$ & $14.3 \mu \mathrm{m}$ & 0.2318 \\
2 & $\mathrm{C}$ & $6 \mathrm{~mm} / \mathrm{s}$ & $\mathrm{SiC}$ & $6 \mu \mathrm{m}$ & 0.2436 \\
3 & $\mathrm{~B}$ & $2 \mathrm{~mm} / \mathrm{s}$ & $\mathrm{SiC}$ & $18 \mu \mathrm{m}$ & 0.2463 \\
4 & $\mathrm{C}$ & $6 \mathrm{~mm} / \mathrm{s}$ & $\mathrm{Quartz}$ & $8 \mu \mathrm{m}$ & 0.2475 \\
5 & $\mathrm{~A}$ & $4 \mathrm{~mm} / \mathrm{s}$ & $\mathrm{SiC}$ & $13.5 \mu \mathrm{m}$ & 0.2813 \\
\hline
\end{tabular}

As is indicated in the above table, it can be concluded that the $\mathrm{C}$ dicing blade has the best overall performance for cutting quartz glass and $\mathrm{SiC}$ under the feed rate of $4 \mathrm{~mm} / \mathrm{s}$ and 6mm/s. With Rockwell hardness is HRA80 90, dicing blade A is suitable to cut alumina ceramics. The comprehensive performance of dicing blade B may meet the requirement of $\mathrm{SiC}$ materials.

\subsection{The influence of tool sharpening on chipping}

The sharpening and trimming of grinding wheel is beneficial to the exposure of diamond grits, which can decrease the cutting chips and tool wear. The cutting spindle current can also decrease because of the sharpening of dicing blade. The common methods to sharpen dicing blade are divided into removing the matrix to expose the diamond particles and breaking diamond grits to produce incisive abrasive point. In this experiment, the first method was used to sharpen dicing blade C. The morphology of cutting grooves are shown in Fig.20 before and after sharpening. According to the calculation of the edge collapse coefficient, the edge chipping after sharpening is greatly reduced, and the spindle current value during cutting is also greatly reduced 
compared with before sharpening. The large cutting current value reflects the poor sharpness of dicing blade decreases.
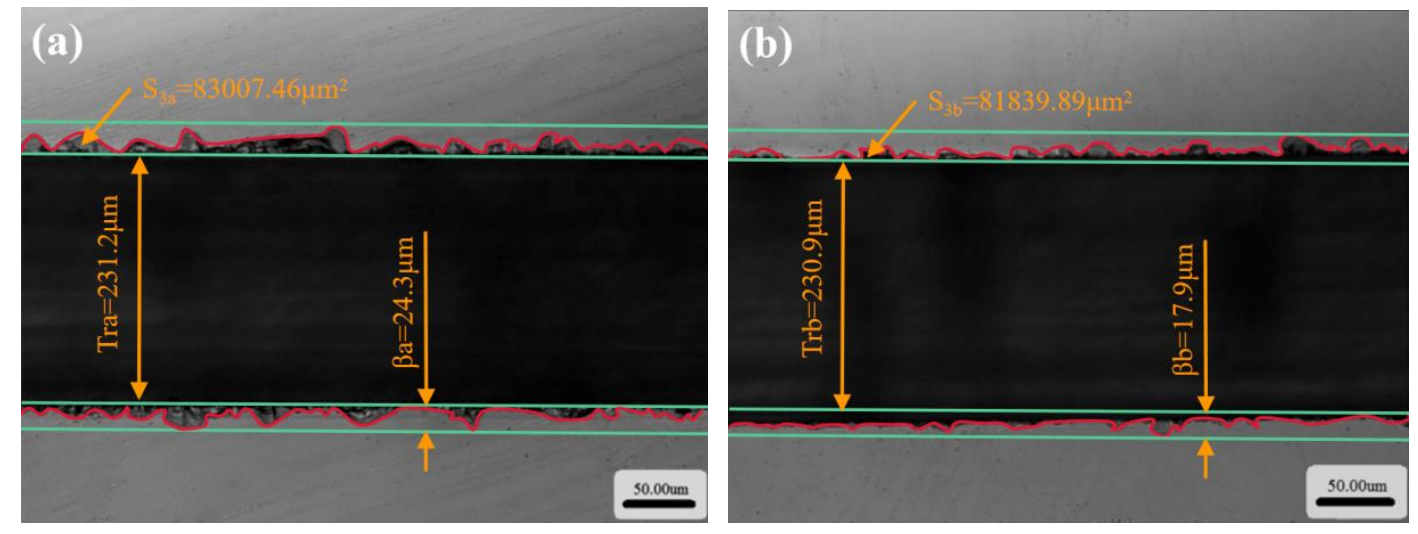

Fig.20. Morphology of cutting grooves with dicing blade before (a) and after sharpening (b).

\subsection{Edge morphology of dicing blade after dicing process}

After cutting quartz glass for a period, the edge structure of dicing blades are different from original shape before cutting. Diamond grits may bare out of matrix because the chips scraps off matrix from dicing blade. Diamond grits will also wear if they do not fall off from the matrix timely. Fig.21 shows the edge morphology of three dicing blades after cutting experiments. As can be seen from the figure, few diamond grits exposes out of the matrix of dicing blade A because the Due to the matrix phases of YA520 and CuZn20 are difficult to wear to expose diamond grits. So the grinding force is relative large when the workpiece was cut with dicing blade A. Dicing blades $\mathrm{B}$ and $\mathrm{C}$ have good exposure of diamond grits because the bonding strength of matrix is proper. And the higher exposure extent of diamond grits also makes the dicing blade sharpness better, resulting in the low deviation coefficient.
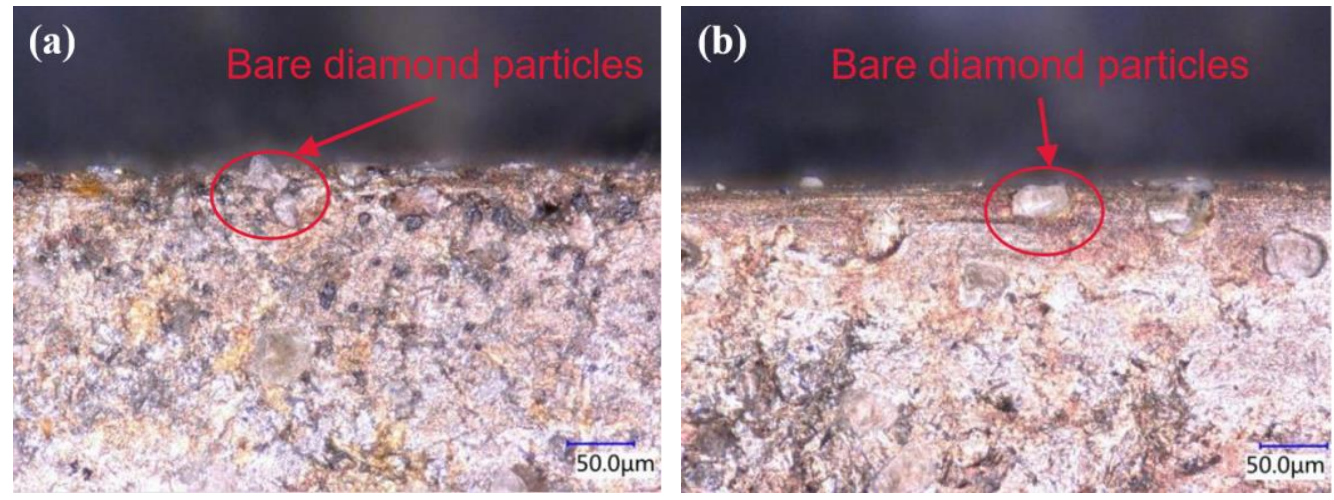


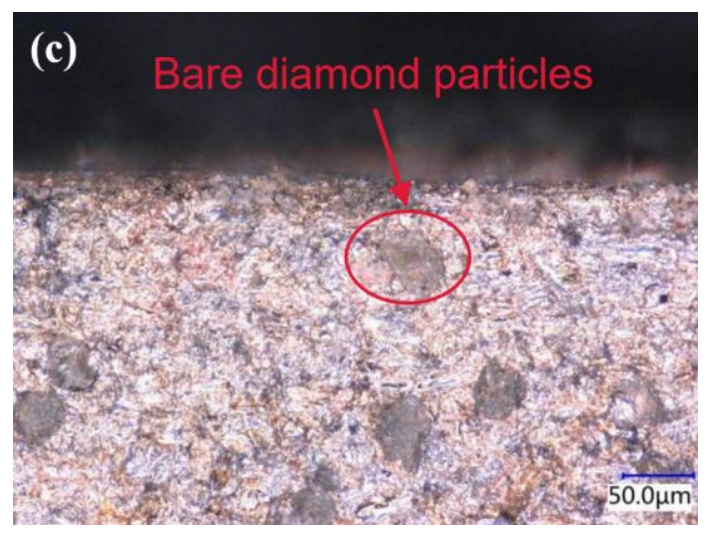

Fig.21.Edge morphology of three dicing blades. (a) dicing blade A, (b) dicing blade B, (c) dicing blade C.

\subsection{Influence of deviation coefficient on crack propagation}

As above discussion, the large deviation coefficient of dicing blade will lead to the large cutting groove width of workpiece. Besides, the deviation coefficient of dicing blade will cause the crack propagation. Qiu[30] and Li[31] studied the effects of interval distance between two scratching grooves on crack propagation and material deformation. The morphology of cutting grooves are not only affected by the cutting internal distance between two grooves, but also are related to the scratching sequence [32]. Therefore, the morphology of cutting grooves are investigated when the cutting internal distance between two grooves was $0.1 \mathrm{~mm}$ with different dicing blades as shown in Fig.22.
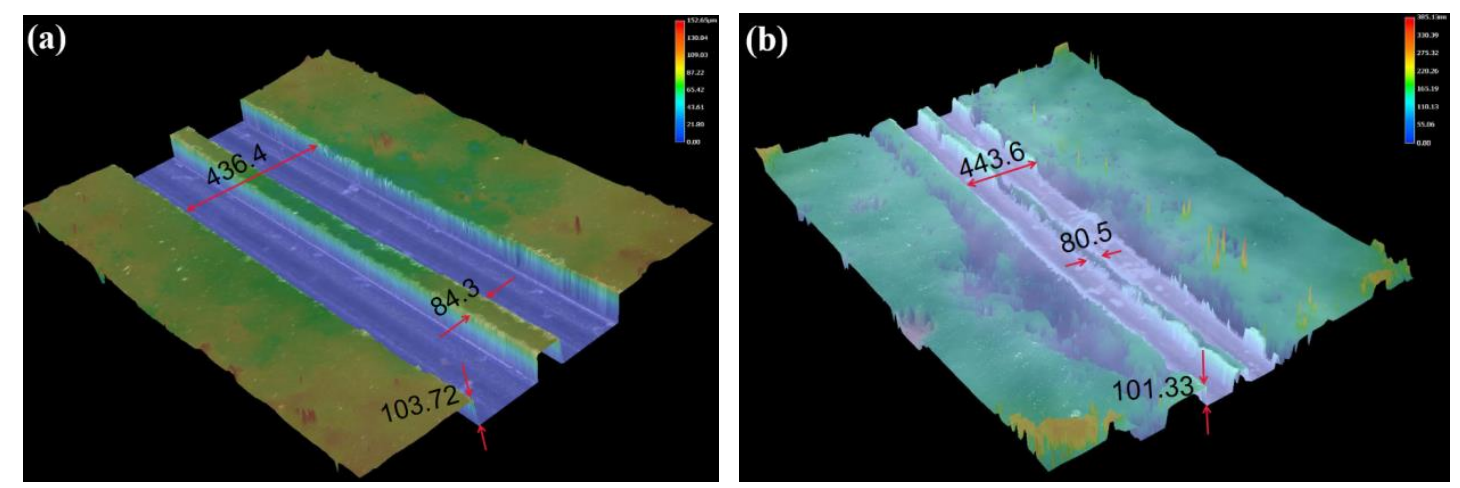


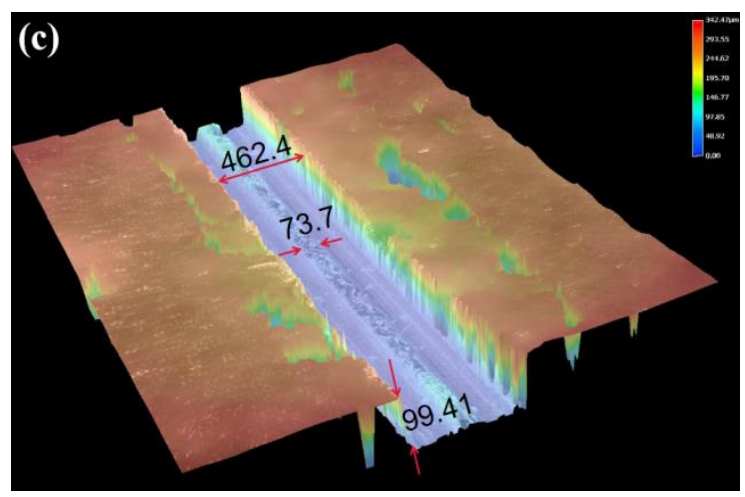

Fig.22. Morphology of cutting grooves with different dicing blades.(a) dicing blade A, (b) dicing blade $\mathrm{B}$, (c) dicing blade $\mathrm{C}$.

As can be seen from the Fig.22 that when the distance between the two cuttings is $0.1 \mathrm{~mm}$, the three dicing blades exhibit different edge chipping effects. There are less chips broken between two grooves when cutting with dicing blade A than that of dicing blade $\mathrm{B}$ and $\mathrm{C}$. The residual width between two cutting grooves when cutting with dicing blade $\mathrm{A}$ is large due to the low deviation coefficients. When cutting with dicing blade $\mathrm{B}$ and $\mathrm{C}$, the material between two grooves is easy to break because of the small residual width. It also indicates that there are less cracks in the edge when cutting with dicing blade A. A lot of lateral cracks in the edge of cutting grooves will lead to the break of the interval material between two grooves.

In addition, it is interesting to find that the chipping in the groove edge of the second knife is more serious than that of the first knife when cutting with dicing blade A. The reason may attribute to that the strength of cutting sheet between two groove has too low to deform. Moreover, it is easy to produce cracks in the side of cutting groove as shown in Fig.23. If the lateral cracks in the side of neighboring grooves connect each other, the cutting sheet between two grooves will break off from the workpiece. Besides, some ridges material occurs on the boundary of cutting groove. 

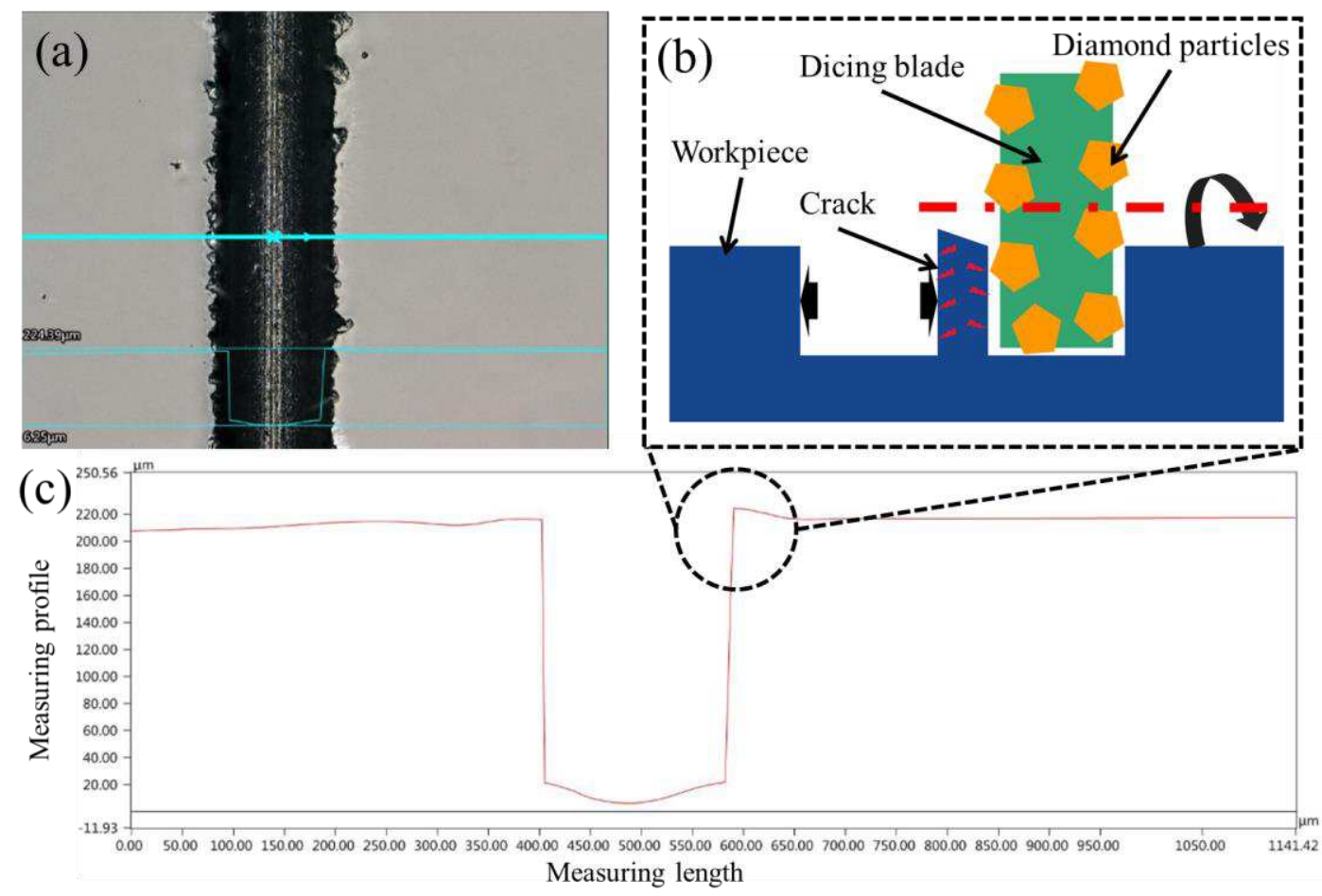

Fig.23. Schematic diagram of dicing groove formation. (a) Cutting groove of quartz glass; (b) protrusions on the boundary of cutting groove; (c) Section profile of cutting groove

\subsection{Relationship between bonding strength and matrix hardness}

The shedding of diamond grits is usually closely related to the hardness of matrix[33]. For metal-based grinding wheels, the diamond grits are mainly held by physical adsorption, chemical bonding and mechanical inlay. The chemical bonding can firmly fix diamond grits. Mechanical inlay is secondly due to the different thermal expansion coefficients of the abrasive particles and the bonding agent, which shrinks during cooling. Extrusion force is generated when the metal-based diamond ultra-thin dicing blade is used; the physical adsorption force is negligible in the metal-based diamond ultra-thin dicing blade. In this case, hydrogen bonds and van der Waals forces become intermolecular forces, which has little effect on the holding of abrasive particles[34].

The unit grinding force has a more obvious impact on the edge chips during precision cutting. Diamond grits need fall off from the matrix timely when the cutting force of single grit is large than a certain value, or else the edge chips will occur because of large cutting force. In order to achieve high cutting quality, it is necessary 
to control the bonding strength between diamond grits and matrix and limit the cutting force of abrasive grits[35]. The abrasive grits will sheds from the dicing blade when the cutting force is large than chemical bonding force and the mechanical inlay force. The shedding force of single particle grits $F_{k p}$ can be expressed as,

$$
F_{k p}=F_{p} t V_{S} \sigma_{N}
$$

Where, $t$ is the grinding time; $\sigma_{N}$ is the metal adhesion coefficient.

It is easy concluded from above analysis that the shedding of diamond grits is related with the bonding strength of matrix when cutting quartz glass and $\mathrm{SiC}$. Here the hardness coefficient is used to characterize the hardness of matrix. According to the components of matrix, the hardness coefficient of dicing blade $\mathrm{A}$ is largest, then is dicing blade $\mathrm{B}$, and last is dicing blade $\mathrm{C}$. Therefore the shedding rate of diamond grits can be calculated and plotted as shown in Fig.24.

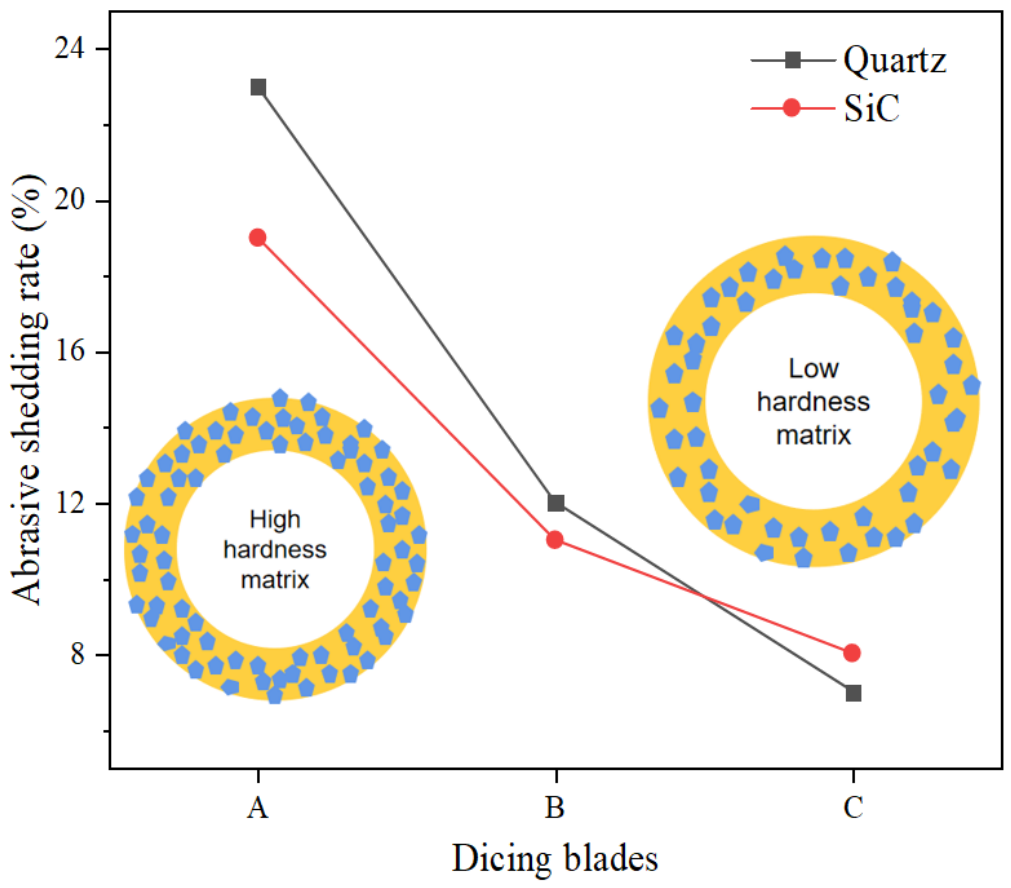

Fig.24. Abrasive shedding rate of different dicing blades

As is indicated in the above figure, the linear relationship between the bonding strength and the shedding of diamond grits can be deduced. When the matrix is soft, diamond grits are easy to expose out of dicing blade during the cutting process. Therefore the diamond grits fall off relatively quickly from the matrix and the self-sharpening effect of dicing blade is good, which results in a reduction of service 
life and an improvement of cutting quality. When the matrix hardness of dicing blade is moderate, the shedding effect at this time is more reasonable. It can meet the self-sharpening requirements during the dicing process. If the matrix of dicing blade is hard, the diamond grits in dicing blade are different to fall off from the matrix. The diamond grits are easy to wear to cause serious chipping damage. So the bonding strength of diamond grits need to be control in small certain range to avoid distinct chipping damage and maintain a proper service life of dicing blade.

\section{Conclusion}

This study analyzes the influence of bonding properties between diamond grits and matrix on the cutting performance of dicing blade by preparing three dicing blades and characterizing the cutting properties of the dicing blades. The concluding results are summarized as follows:

(1) The cutting performance is influenced by various factors. The components of dicing blade can be classified into eight kinds according to their different roles, including sharpening element, strengthening element, supporting element, combination element, wear resistance element, reductant element, toughening element and moistening element. Essentially, the bonding properties of dicing blade decide the cutting force of diamond grits acting on workpiece and dominate the cutting quality of workpiece.

(2) The hardness of matrix in dicing blade has significant influence on the exposure extent of diamond grits. The soft matrix is easy removed by chips from dicing blade in dicing process so as to expose diamond grits. However the dicing blade with soft matrix is easy to deform during dicing process. It results that the deviation coefficient of dicing blade $\mathrm{C}$ is larger than that of dicing blade $\mathrm{A}$ and dicing blade B.

(3) According the experimental results, the spindle current is a novel index to reflect the grinding force in cutting process if the dynamometer is difficult used. The spindle current increases with dicing distance when cutting with different feed rate. 
The prediction of grinding force obtained by analyzing the scratching process of single diamond grit is close with the experimental results. Dicing blade C possesses the lowest cutting force due to its good abrasive exposure. Besides, the cutting quality become better if the dicing blade is sharpened after using for a period.

(4) The unit chipping coefficient by observing the morphology of cutting grooves can reflect the number of dicing chips and the size of maximum chip. The dicing blade $\mathrm{C}$ with good exposure extent of diamond grits can obtain lower unit chipping coefficient. The cutting quality with dicing blade is superior to other two dicing blade. Moreover, it is easy to produce cracks in the side of cutting groove. If the lateral cracks in the side of neighboring grooves connect each other, the cutting sheet between two grooves will break off from the workpiece.

\section{Acknowledge}

This research was supported by the National Natural Science Foundation of China (Grant No. 51305278), LiaoNing Revitalization Talents Program, China (Grant No. XLYC2007133) and the Natural Science Foundation of Liaoning Province, China (Grant No. 2020-MS-213).

\section{Compliance with Ethical Standards}

The authors declare that they have no conflict of interest. The authors have no relevant financial or non-financial interests to disclose.

\section{References}

[1] Yuan Z, Cheng K, Zhang Y, Hu J, \& Zheng P (2019). Investigation on the fabrication of dicing blades with different sintering methods for machining hard-brittle material wafers. P I Mech. Eng. B-J Eng., 233(7): 1781-1793. https://doi.org/10.1177/0954405418802302

[2] Dong X, Shin Y.C (2017) Improved machinability of SiC/SiC ceramic matrix composite via 
laser-assisted micromachining. Int J Adv Manuf Technol 90: 731-739. https://doi.org/10.1007/ s00170-016-9415-5

[3] Han W, Kunieda M (2020) Precision electrochemical machining of tungsten micro-rods using wire electrochemical turning method. Int J Adv Manuf Technol 111: 295-307. https://doi.org/10.1007/s00170-020-06127-7

[4] M. Stompe, P.v. Witzendorff, S. Cvetkovic,... \& L. Rissing (2012) Concept for performance-enhancement of ultra-precision dicing for bulk hard and brittle materials in micro applications by laser dressing. Microelectronic Engineering 98: 544-547. https://doi.org/10.1016/j.mee.2012.07.033

[5] Miao X, Qiang Z, Wu M. et al (2020) Correction to: The optimal cutting times of multipass abrasive water jet cutting. Int J Adv Manuf Technol 106, 2669 . https://doi.org/10.1007/s00170-019-04855-z

[6] Yuan Z, Hu J, Wen Q, Cheng K, Zheng P (2018) Investigation on an innovative method for high-speed low-damage micro-cutting of CFRP composites with diamond dicing blades. Materials. 11(10):1974. https://doi.org/10.3390/ma11101974

[7] Yu X, Zhao W, Huang S, Zhou L (2012) Surface formation mechanism of grinded $\mathrm{SiC}_{\mathrm{p}} / \mathrm{Al}$ composite with high volume fraction. Journal of Shenyang University of Technology, 34(06): 666-670. https://doi:CNKI:21-1189/T.20121109.1417.011

[8] Li M, Zhang F, Zhou Y, \& Wu S (2020) Preparation and performance of resin-bonded grinding wheel with braze-coated diamond grits. Diam. Relat. Mater. (101) 107619. https://doi.org/10.1016/j.diamond.2019.107619

[9] Wang J, Zhao Q, Zhang C. et al (2021) Arc envelope grinding of sapphire steep aspheric surface with sic-reinforced resin-bonded diamond wheel. Int. J. of Precis. Eng. and Manuf.-Green Tech. 8, 1083-1094. https://doi.org/10.1007/s40684-020-00225-3

[10] Tang Y, He W (2010) Research and application status of ultra-thin diamond dicing blade. Superhard Material Engineering, 22(06):34-37. https://doi:CNKI:SUN:ZBKJ.0.2010-06-011

[11] Zhou H, Wang C, Zhao D. et al (2012) Nanogrinding of soft-brittle monocrystalline mercury cadmium telluride using a ceramic bond ultrafine diamond grinding wheel. Int J Adv Manuf Technol 60, 933-938. https://doi.org/10.1007/s00170-011-3667-x

[12] Chen K, Liu Y, Cao C, Liu W (2018) Performance optimization of Al-based bond matrix in 
metallic bond diamond wheel. Diamond \& Abrasives Engineering, 38(02): 20-25. https://doi:10.13394/j.cnki.jgszz.2018.2.0005

[13] Monteverde F (2008) Hot pressing of hafnium diboride aided by different sinter additives. J Mater. Sci., 43, 1002-1007. https://doi.org/10.1007/s10853-007-2247-9

[14] Yu Z, Zhao P \&amp, Hu F (2018) Study on UV curing behavior and properties of ES/CEP blend resin. Material guide (02), 263-267.https://doi:CNKI:SUN:CLDB.0.2018-02-021

[15] S.B. Lee, Y. Tani, T. Enomoto \& H. Sato (2005) Development of a dicing blade with photopolymerizable resins for improving machinability. CIRP Annals - Manufacturing Technology(1), 293-296. https://doi.org/10.1016/S0007-8506(07)60106-1

[16] Hai J, Dong Y, Jason Tam \& Uwe Erb (2019) Effects of diamond particle size on the formation of copper matrix and the thermal transport properties in electrodeposited copper-diamond composite materials. J. Alloys Compd., 791, 1128-1137, https://doi.org/10.1016/j.jallcom.2019.03.347

[17] Staniewicz-Brudnik B, Karolus M, Bączek E. et al (2018) The influence of the diamond wheel grinding process on the selected properties of boron nitride dispersion in cemented carbide (BNDCC) composites. Int J Adv Manuf Technol 95, 1437-1450 . https://doi.org/10.1007/s00170-017-1318-6

[18] Yang L, Wang T, Liu C, Ma Y, Wu L, Yan H \& Liu W (2021) Microstructures and mechanical properties of AZ31 magnesium alloys fabricated via vacuum hot-press sintering. J. Alloys Compd. 2021, 870:159473.. https://doi.org/10.1016/j.jallcom.2021.159473

[19] Joshua Gild, Kevin Kaufmann, Kenneth Vecchio \& Jian L (2019) Reactive flash spark plasma sintering of high-entropy ultrahigh temperature ceramics. Scripta Materialia,170, 106-110. https://doi.org/10.1016/j.scriptamat.2019.05.039

[20] Chen S, Lin S (2011) Study of an on-line precision microgroove generating process on silicon wafer using a developed ultra-thin diamond wheel-tool. Diam. Relat. Mater., 20(3) 339-342. https://doi.org/10.1016/j.diamond.2011.01.033

[21] Su Z, Zhang S, Wu J, Liu L (2021) Cutting performance evaluation of nickel-plated graphite Fe-based diamond saw blades. Diam. Relat. Mater., 114,. https://doi.org/10.1016/j.diamond.2021.108344

[22] He L, Zhang S, Guo H (2014). Electrical discharge thinning process of diamond ultrathin 
cutting wheel. Superhard Material Engineering, 26(01):5-10. https://doi:CNKI:SUN:ZBKJ.0.2014-01-002

[23] Wang J (2015) The experimental study on key manufacture technology of precision super hard abrasive ultra-thin grinding wheel. Dissertation, Henan University of Technology.

[24] Guo Q (2016). The application of copper based bond of new diamond tools and its properties.

Chemical Engineering Design Communications, 42(09): 99-109. https://doi:CNKI:SUN:WGTX.0.2016-09-079

[25] Nadolny K, Kieraś S, Sutowski P (2021) Modern approach to delivery coolants, lubricants and antiadhesives in the environmentally friendly grinding processes. Int. J. of Precis. Eng. and Manuf. Green Tech. 8, 639-663. https://doi.org/10.1007/s40684-020-00270-y

[26] Xiu S, Liu M, Zhang X, Bai B (2014) Grinding contact area and grinding force modeling based on impact principle. Journal of Northeastern University (Natural Science). 35(02):268-272. https://doi:CNKI:SUN:DBDX.0.2014-02-026

[27] Zhang J, Ge P, Zhang L (2007). Research on the grinding force based on the probability $\begin{array}{llll}\text { statistics. } & \text { China 20:2399-2402. }\end{array}$ https://doi:CNKI:SUN:ZGJX.0.2007-20-001

[28] Wan M, Wen D, Ma Y, Zhang W (2019) On material separation and cutting force prediction in micro milling through involving the effect of dead metal zone. Int J Mach Tool Manu,146, 103452. https://doi.org/10.1016/j.ijmachtools.2019.103452

[29] Yan L, Jiang F, Rong Y (2012) Grinding mechanism based on single grain cutting simulation. J. Mech. Eng., 48(11):172-182. https://doi:CNKI:SUN:JXXB.0.2012-11-022

[30] Qiu Z, Liu C, Wang H, et al (2016) Crack propagation and the material removal mechanism of glass-ceramics by the scratch test. J Mech Behav Biomed Mater., 64:75-85. https://doi.org/10.1016/j.jmbbm.2016.07.021

[31] Li C, Zhang F, Wang X, et al (2018) Repeated nanoscratch and double nanoscratch tests of $\mathrm{Lu}_{2} \mathrm{O}_{3}$ transparent ceramics: Material removal and deformation mechanism, and theoretical model of penetration depth. J. Eur. Ceram. Soc., 38(2):705-718. https://doi.org/10.1016/j.jeurceramsoc.2017.09.028

[32] Zhang P, Zhao H, Shi C, et al (2013) Influence of double-tip scratch and single-tip scratch on nano-scratching process via molecular dynamics simulation. Appl. Surf. Sci., 280, 751-756. 
https://doi.org/10.1016/j.apsusc.2013.05.056

[33] Sokhan' S.V, Voznyy V.V, Redkin A.S. et al (2020) Wear of a Diamond Wheel during Grinding of Ceramic Balls Made of Silicon Carbide. J. Superhard Mater. 42, 432-442. https://doi.org/10.3103/S1063457620060106

[34] Zhao X, Duan L, Chekhotkin V.F, Weng H (2015) Summary on holding force of metallic matrix to diamond. Diam. Relat. Mater., 35(06):41-46. https://doi:10.13394/j.cnki.jgszz.2015.6.0009

[35] Xie Q (2020) Study on abrasives holding force and mechanical properties of electroplated diamond wire saw. Dissertation, Shandong University. 